\title{
Early Synapse Formation in Developing Interneurons of the Adult Olfactory Bulb
}

\author{
Patrizia Panzanelli, ${ }^{1}$ Cedric Bardy, ${ }^{2,3}$ Antoine Nissant, ${ }^{2,3}$ Marta Pallotto, ${ }^{1,2,3}$ Marco Sassoè-Pognetto, ${ }^{1}$ \\ Pierre-Marie Lledo, ${ }^{2,3}$ and Jean-Marc Fritschy ${ }^{4}$ \\ ${ }^{1}$ Department of Anatomy, Pharmacology and Forensic Medicine, and National Institute of Neuroscience-Italy, University of Turin, 10126 Turin, Italy, \\ ${ }^{2}$ Perception and Memory Laboratory, ${ }^{3}$ Unité de Recherche Associée 2182, Centre National de la Recherche Scientifique, Institut Pasteur, 75724 Paris, \\ France, and ${ }^{4}$ Institute of Pharmacology and Toxicology, University of Zurich, CH-8057 Zurich, Switzerland
}

New olfactory bulb granule cells (GCs) are GABAergic interneurons continuously arising from neuronal progenitors and integrating into preexisting bulbar circuits. They receive both GABAergic and glutamatergic synaptic inputs from olfactory bulb intrinsic neurons and centrifugal afferents. Here, we investigated the spatiotemporal dynamic of newborn GC synaptogenesis in adult mouse olfactory bulb. First, we established that GABAergic synapses onto mature $\mathrm{GC}$ dendrites contain the $\mathrm{GABA}_{\mathrm{A}}$ receptor $\alpha 2$ subunit along with the postsynaptic scaffolding protein gephyrin. Next, we characterized morphologically and electrophysiologically the development of GABAergic and glutamatergic inputs onto newborn GCs labeled with eGFP (enhanced green fluorescent protein) using lentiviral vectors. Already when reaching the GClayer (GCL), at $3 \mathrm{~d}$ post-vector injection (dpi), newborn GCs exhibited tiny voltage-dependent sodium currents and received functional GABAergic and glutamatergic synapses, recognized immunohistochemically by apposition of specific presynaptic and postsynaptic markers. Thereafter, GABAergic and glutamatergic synaptic contacts increased differentially in the GCL, and at 7 dpi, PSD-95 clusters outnumbered gephyrin clusters. Thus, the weight of GABAergic input was predominant at early stages of GC maturation, but not later. Newborn GC dendrites first reached the external plexiform layer at $4 \mathrm{dpi}$, where they received functional GABAergic contacts at $5 \mathrm{dpi}$. Reciprocal synapses initially were formed on GC dendritic shafts, where they might contribute to spine formation. Their presence was confirmed ultrastructurally at $7 \mathrm{dpi}$. Together, our findings unravel rapid synaptic integration of newborn GCs in adult mouse olfactory bulb, with GABAergic and glutamatergic influences being established proximally before formation of output synapses by apical GC dendrites onto mitral/tufted cells.

\section{Introduction}

Adult neurogenesis is a developmental process encompassing the formation and integration of newborn neurons into existing neural circuits (Ming and Song, 2005). In adult mammalian brain, neurogenesis has been clearly documented in the dentate gyrus and olfactory bulb (OB) (Altman, 1969; Alvarez-Buylla and Garcia-Verdugo, 2002; Kempermann et al., 2004). In the latter, newborn neurons originate in the subventricular zone (SVZ), migrate along the rostral migratory stream (RMS), and differentiate into GABAergic interneurons, including granule cells (GCs) and periglomerular cells (PGCs). Between 10,000 and 30,000 adult-generated neurons migrate daily into the $\mathrm{OB}$, and experi-

Received June 25, 2009; revised 0ct. 14, 2009; accepted 0ct. 16, 2009.

This work was supported by Compagnia di San Paolo and Regione Piemonte (Ricerca Sanitaria Finalizzata 2006 and 2008), the Swiss National Science Foundation, Fondation pour la Recherche Médicale ("Equipe FRM"), Groupe Arpège, Agence Nationale de la Recherche Grant ANR-2007-SEST-01503, and Ecole des Neurosciences de Paris. M.P. is the recipient of a doctoral fellowship from "Università Italo-Francese" (Progetto Vinci). We are grateful to Kerren Murray for preparing the lentivectors and Irina Nikonenko and Dominique Muller (University of Geneva) for support with serial EM analysis.

Correspondence should be addressed to either of the following: Dr. Patrizia Panzanelli, Department of Anatomy, Pharmacology and Forensic Medicine, University of Turin, Corso Massimo D'Azeglio, 52, 10126 Turin, Italy, E-mail: patrizia.panzanelli@unito.it; or Dr. Pierre-Marie Lledo, Pasteur Institute, 25 rue du Dr Roux, Centre National de la Recherche Scientifique Unité de Recherche Associée 2182,75724 Paris, France, E-mail: pmlledo@pasteur.fr.

DOI:10.1523/JNEUROSCI.3034-09.2009

Copyright $\odot 2009$ Society for Neuroscience ～0270-6474/09/2915039-14\$15.00/0 mental evidence supports activity-dependent regulation of cell proliferation, synaptic integration, and neuronal survival (Lledo et al., 2006). Among the multiple mechanisms involved, GABAergic signaling plays an important role in the control of early neurogenic steps, including neuronal proliferation in the SVZ and neuroblast migration along the RMS (Bordey, 2007; Platel et al., 2008). The contribution of GABAergic signaling to later stages, including synaptic integration and survival of newborn neurons, has not yet been explored.

GCs are the most abundant subtype of GABAergic interneuron in the OB. They inhibit the principal neurons, mitral and tufted cells $(\mathrm{M} / \mathrm{T})$, by reciprocal dendrodendritic synapses located in the external plexiform layer (EPL) (Shepherd et al., 2004) and containing the $\mathrm{GABA}_{\mathrm{A}}$ receptor $\left(\mathrm{GABA}_{\mathrm{A}} \mathrm{R}\right)$ subunit $\alpha 1 / \alpha 3$ (Panzanelli et al., 2005; Lagier et al., 2007). Functionally, this synaptic arrangement underlies both feedback and lateral inhibition, which are important for odor discrimination (Lledo and Lagier, 2006). GABA release from GCs also contributes to synchronize M/T firing and constrains $\mathrm{M} / \mathrm{T}$ rhythmic activity in the gamma range (Kashiwadani et al., 1999; Nusser et al., 2001; Lagier et al., 2004, 2007). The firing activity of GCs is tightly controlled by GABAergic and glutamatergic synaptic inputs. The former originate from local interneurons (Eyre et al., 2008), whereas glutamatergic synapses stem from $\mathrm{M} / \mathrm{T}$ and centrifugal afferents (Balu et al., 2007). 
Functional analyses of adult-generated GCs revealed that GABA and glutamate ionotropic receptors appear early during maturation (Belluzzi et al., 2003; Carleton et al., 2003). Two studies using retroviruses to label newborn neurons in adult rodents have revealed a proximal-to-distal gradient of excitatory synapse formation on GC dendrites, suggesting that synaptogenesis is spatially regulated during neuronal maturation (Whitman and Greer, 2007; Kelsch et al., 2008). However, based on the assumption that GCs mostly receive excitatory input, these studies paid little attention to input GABAergic synapses.

Here, we investigated morphologically and functionally the spatiotemporal dynamic of synaptogenesis in adult-generated GCs of the adult mouse OB, focusing mainly on GABAergic contacts. First, using immunohistochemistry at the light- and electron-microscopic level, we determined that GABAergic synapses formed onto mature GC dendrites contain the $\mathrm{GABA}_{\mathrm{A}} \mathrm{R} \alpha 2$ subunit along with the postsynaptic scaffolding protein gephyrin. Second, using a combined electrophysiological and immunohistochemical approach, we analyzed the development and distribution of synapses received and made by newborn GCs transduced with enhanced green fluorescent protein (eGFP)-encoding lentiviral vectors injected into the RMS (Consiglio et al., 2004; Grubb et al., 2008). Since newborn cells migrate rapidly into the GC layer (GCL), we precisely monitored the timing of initial synaptogenesis by focusing our analysis onto early stages of maturation, between 3 and $7 \mathrm{~d}$ post-vector injection (dpi).

\section{Materials and Methods}

Animals

All experiments were conducted in accordance with the Charter of Fundamental Rights of the European Union (2000/C 364/01), the European Communities Council Directive of 24 November 1986 (86/609/EEC), and were approved by the Animal Care and Use Committees of our institutions. The generation of GAD67-eGFP $(\Delta$ neo $)$ mice, which express eGFP selectively in GABAergic neurons under the control of the endogenous GAD67 gene promoter, has been described previously (Tamamaki et al., 2003). In the present study, these transgenic mice are called GAD67-GFP mice for simplicity. They were bred at the University of Zurich by crossing heterozygous animals with C57BL/6J mice and genotyped by PCR analysis of tail biopsies. We used six mutant and four wild-type mice for light microscopy and three mutant mice for electron microscopy analysis of GABAergic synapses onto GCs. For viral injections, we used 8- to 10-week-old male C57BL/6J mice ( $n=55$; Janvier). Electrophysiological experiments and morphological analysis were performed between 3 and 21 dpi.

\section{Lentiviral vectors}

For cytosolic eGFP labeling, a custom-built lentivirus containing the gene for GFP and controlled by phosphoglycerate kinase (PGK) promoter was used to transduce adult-born neurons as previously described (Consiglio et al., 2004; Grubb et al., 2008). Briefly, virus at $2.2 \times 10^{10}$ $\mathrm{U} / \mathrm{ml}$ were stored at $-80^{\circ} \mathrm{C}$. Immediately before injection, the vectors were diluted in PBS to obtain a final concentration of $15 \mathrm{ng}$ of p24 protein $/ \mu$ l.

\section{Stereotaxic surgery}

For stereotaxic injections of lentivirus, adult mice were anesthetized with intraperitoneal injection of xylazine $(0.25 \mathrm{mg}$; Rompun; Bayer Health Care) followed by ketamine ( $2.5 \mathrm{mg}$; Imalgene; Merial). A small craniotomy was performed at the injection site. To minimize any resultant heterogeneity in cell age reaching the $\mathrm{OB}$ circuit, we performed virus injections in the RMS at the following coordinates in each hemisphere: anteroposterior, $+3.3 \mathrm{~mm}$ from bregma; mediolateral, $\pm 0.82 \mathrm{~mm}$; dorsoventral, $-2.85 \mathrm{~mm}$ from the pial surface. Viruses specifically labeled adult-born migrating neuroblasts, since subsequent inspection of $\mathrm{OB}$ sections revealed eGFP expression only in GCs and PGCs. Diffusion from the injection site was not sufficient to label resident OB cells.
Immunofluorescence and confocal laser scanning microscopy

Mice were deeply anesthetized with isoflurane and swiftly decapitated. The OB was dissected out and cut in coronal slabs that were fixed by immersion in $4 \%$ paraformaldehyde in $0.1 \mathrm{~m}$ sodium phosphate buffer, pH 7.4, for $15 \mathrm{~min}$ (for details, see Sassoè-Pognetto et al., 2000). For virus-injected mice, acute $300-\mu \mathrm{m}$-thick horizontal slices of the OB prepared with a Leica Vibratome (VT 1000S) were placed in bubbled artificial CSF (ACSF) for $30 \mathrm{~min}$ at $35^{\circ} \mathrm{C}$ and fixed by immersion in $4 \%$ paraformaldehyde at room temperature for $12 \mathrm{~min}$, as described previously (Schneider Gasser et al., 2006). After fixation, all tissues were rinsed in PBS, cryoprotected in 30\% buffered sucrose, and sectioned with a cryostat. Sections were mounted on gelatin-coated slides and stored at $-20^{\circ} \mathrm{C}$. Double and triple immunofluorescence staining was performed as described previously (Panzanelli et al., 2005), using various combination of primary antibodies raised in different species. The following primary antibodies were used: guinea pig antibodies against the $\mathrm{GABA}_{\mathrm{A}} \mathrm{R}$ $\alpha 1, \alpha 2$, or $\alpha 3$ subunit (Fritschy and Mohler, 1995), gephyrin (monoclonal mAb7a; Synaptic Systems), PSD-95 (mAb; Neuromab), vesicular GABA transporter (VGAT) (guinea pig; Millipore Bioscience Research Reagents), vesicular glutamate transporter 1 (VGLUT1) (guinea pig; Millipore Bioscience Research Reagents), doublecortin (guinea pig; Millipore Bioscience Research Reagents), and eGFP (rabbit; Synaptic Systems). All secondary antibodies were raised in donkey and conjugated to Alexa 488 (Invitrogen), Cy3, or Cy5 (Jackson Immunoresearch). The sections were analyzed by epifluorescence microscopy (Zeiss Imager equipped with an Apotome module) and high-magnification images of eGFP-positive newborn GCs and their dendrites were acquired by confocal laser-scanning microscopy (Zeiss LSM5 Pascal) using sequential acquisition of separate wavelength channels to avoid fluorescence cross talk. Stacks of $12-15$ confocal sections $(512 \times 512$ pixels; $90 \mathrm{~nm} /$ pixel $)$ spaced $250-400 \mathrm{~nm}$ were acquired with $100 \times$ objective (1.4 numerical aperture) with the pinhole set at 1 Airy unit. For display, images were processed with the image analysis software Imaris (version 4.3; Bitplane).

\section{Image analysis}

Quantification of the number of gephyrin- and $\alpha 2$ subunit-positive postsynaptic clusters in four wild-type mice was performed on single eight bit confocal images using the software NIH ImageJ. Clusters were defined based on intensity (25-30\% of maximal intensity) and size (minimal area, $0.07 \mu \mathrm{m}^{2}$ ). The analysis was performed separately in the glomerular layer (GL), outer EPL, inner EPL, inner plexiform layer (IPL), and GCL in four mice. In tissue from virus-injected mice, all quantifications were performed on 20-60 individual dendritic segments measured in images from at least three different mice at each time point. Synaptic clusters (labeled for gephyrin or PSD-95) in eGFP-positive structures were defined based on colocalization analysis of images from two channels. Colocalized clusters were tagged with a separate color and manually counted in eGFP-positive dendrites. The density of clusters was calculated based on dendritic length and soma perimeter measured manually (see Table 1). Visualization of GABAergic synaptic contacts received by eGFP-positive dendrites likewise was performed by colocalization analysis. VGAT-positive terminals were considered to be presynaptic when contacting an eGFP-positive dendrite or spine on at least four adjacent pixels. In contrast, VGAT-positive puncta completely enclosed within an eGFP-positive dendrite were considered to represent VGAT protein expressed by this newborn GC and transported toward the EPL. Formation of reciprocal synapses was assessed by colocalization analysis based on the apposition of $\alpha 1 / \alpha 3$ subunit-positive clusters with PSD-95-positive clusters (present in M/T cells) in the immediate vicinity of eGFP-positive dendrites or spines. Apposition was defined by contact of at least four adjacent pixels. Three populations of clusters were observed $(\alpha 1+\alpha 3$, PSD-95, or "apposed") and quantified (see Table 2).

\section{Statistical analysis}

Data are shown as mean \pm SEM. Statistical analyses were performed using two-way ANOVA, followed where appropriate by a post hoc test (Bonferroni's post test). All analyses, including analysis of parameter correlations, were performed using Prism software (version 4.01; GraphPad). 


\section{Preembedding electron microscopic immunohistochemistry}

Three GAD67-GFP mice and six virus-injected mice were anesthetized as above and perfused with $2 \%$ paraformaldehyde and $0.1 \%$ glutaraldehyde in sodium acetate buffer, $\mathrm{pH}$ 6, for $2 \mathrm{~min}$ followed by $1 \mathrm{~h}$ perfusion with $2 \%$ paraformaldehyde and $0.1 \%$ glutaraldehyde in $0.1 \mathrm{~m}$ borate buffer, pH 9 (Kollo et al., 2008). The brain was taken out and postfixed for $2 \mathrm{~h}$. Then, the $\mathrm{OB}$ was dissected out and cut into $70 \mu \mathrm{m}$ coronal sections with a Vibratome. The sections were cryoprotected with 30\% sucrose and frozen and thawed three times to enhance the antibody penetration. Sections were blocked in 10\% NGS in TBS, pH 7.4, and incubated with primary antibodies (gephyrin in combination with GFP) diluted in TBS. The sections were then incubated with secondary antibodies coupled to biotin (1:250; Vector Laboratories) and to $1.4 \mathrm{~nm}$ colloidal gold particles (1:200; Nanoprobes), followed by an immunoperoxidase reaction (Vectastain Elite; Vector Laboratories). Ultrasmall gold particles were visualized with the gold enhance-EM formulation (Nanoprobes) as described by the manufacturer. The sections were treated with $0.5 \% \mathrm{OsO}_{4}$ and $1 \%$ uranyl acetate, dehydrated, and embedded into Epon 812. Ultrathin sections were collected on copper single-hole grids. Serial thin sections were cut in the EPL; eGFP-positive profiles were analyzed in images taken from at least 10 sections at a magnification of $13,500 \times$. They were observed and photographed in a JEM-1010 transmission electron microscope (Jeol) equipped with a side-mounted CCD camera (Mega View III; Soft Imaging System).

\section{Electrophysiology}

Slice preparation. Mice were deeply anesthetized with isoflurane (Mundipharma) and then swiftly decapitated. Horizontal slices from the OB and frontal cortices were made after decapitation and brain removal. After cutting, slices $(300 \mu \mathrm{m})$ were placed in oxygenated ACSF at $35^{\circ} \mathrm{C}$ for $30 \mathrm{~min}$ and kept in bubbled ACSF at room temperature. The ACSF contained $124 \mathrm{~mm} \mathrm{NaCl}, 3 \mathrm{~mm} \mathrm{KCl}, 1.3 \mathrm{~mm} \mathrm{MgSO}_{4}, 26 \mathrm{~mm} \mathrm{NaHCO}_{3}$, $1.25 \mathrm{~mm} \mathrm{NaHPO}_{4}, 20 \mathrm{~mm}$ glucose, and $2 \mathrm{~mm} \mathrm{CaCl}$ (all chemicals were from Sigma-Aldrich).

Whole-cell patch-clamp recordings. Individual slices were placed in a submerged type recording chamber and continuously perfused $(3 \mathrm{ml} /$ $\mathrm{min})$ at room temperature. Whole-cell voltage-clamp recording from GC was performed using a $40 \times$ water-immersion objective, a halogen light source, differential interference contrast filters (all Olympus), a CCD camera (Hamamatsu C7500), and a Heka EPC9/2 amplifier. Patch electrodes $(8-13 \mathrm{M} \Omega)$ were filled with an internal solution $(126 \mathrm{~mm}$ Cs-gluconate, $6 \mathrm{~mm} \mathrm{CsCl}, 2 \mathrm{~mm} \mathrm{NaCl}, 10 \mathrm{~mm}$ Na-HEPES, $10 \mathrm{~mm}$ D-glucose, 0.2 mм Cs-EGTA, 0.3 mm GTP, 2 mm Mg-ATP, 0.2 mм cAMP, and $0.15 \%$ biocytin, $\mathrm{pH} 7.3,290-300 \mathrm{mOsm}$ ). Liquid junction potentials $(10 \mathrm{mV})$ were compensated. Before placing the stimulating electrode, voltage-dependent sodium currents induced by applying to the cell series of depolarizing pulses (holding potential, $-70 \mathrm{mV}$; increasing pulse step of $5 \mathrm{mV}$ ).

Recordings were filtered at $10 \mathrm{kHz}$ (filter 1) and $2.9 \mathrm{kHz}$ (filter 2), digitized, and sampled at intervals of $20-50 \mu \mathrm{s}(50-20 \mathrm{kHz})$ according to the demands of individual protocols. To control the stability of the patch throughout the recordings, the series and membrane resistances were monitored.

The recording pipettes were loaded with rhodamine to be sure that the recorded cells (rhodamine-positive) were newborn (eGFP-positive). Colocalization of eGFP and rhodamine were confirmed using a digital camera (Evolution VF; MediaCybernetics) and its software (Image-Pro Express 6).

Electrical stimulations. Synaptic responses were evoked using a small monopolar stimulating glass pipette (3-4 $\mu \mathrm{m}$ tip diameter, pulled from $1.5 \mathrm{~mm}$ outer diameter, $1.17 \mathrm{~mm}$ inner diameter borosilicate glass, and filled with ACSF), finely positioned using a micromanipulator. The electrodes were placed in the GCL closed to the soma of the recorded cells to evoke optimal responses. In another set of experiments designed to reveal the presence of functional synapses in the EPL, the electrodes were placed in the EPL just above the mitral cell layer (MCL). Preceded by a short test pulse of $-5 \mathrm{mV}$, two consecutive stimuli were delivered with an interval of $150 \mathrm{~ms}$. At least 30 repeats interleaved with $10 \mathrm{~s}$ were recorded for each cell. The strength of stimulation $(\sim 100 \mu \mathrm{A}$ for $100 \mu \mathrm{s})$ was adjusted to evoke maximal responses.

Focal drugs application. Puffs of gabazine (SR-95531) (100 $\mu \mathrm{M})$ were delivered locally using a Pneumatic PicoPump (PV820) and a glass pipette (3-4 $\mu \mathrm{m}$ tip diameter). The duration $(50-150 \mathrm{~ms})$ and pressure (10-15 psi) were adjusted to obtain an optimal diffusion of the solution. The covered area was visualized with the presence of Fast-Green FCF (Sigma-Aldrich) in the pipette.

Analysis. The recordings were analyzed off-line with custom-designed Matlab programs (MathWorks). Exclusion of the sweeps displaying abnormal variability was assisted by criterion set in the Matlab routine (e.g., resistance series or baseline $>3 \mathrm{SD}$ from the mean). Success rates (number of evoked responses/total number of stimulation) were also quantified using Matlab routine (e.g., failure if poststimulation peak amplitude $<5 \mathrm{pA}$ ). The automatized selection of failures and evoked responses was graphically monitored, and only on the odd occasion cells required slight readjustments of the criterion.

The mean current amplitudes, $20-80 \%$ rise times, and decay times were obtained by averaging only the successful evoked responses obtained from the first stimulus. The paired-pulse ratios were measured only from recordings in which each of the two consecutive stimuli (interval $150 \mathrm{~ms}$ ) successfully evoked a response.

Decay time were derived by fitting the formula $f(t)=a^{*} \exp \left(-t / t_{\mathrm{f}}\right)+$ $b^{\star} \exp \left(-t / t_{\mathrm{s}}\right)$, where $a$ and $b$ are the peak amplitude of fast and slow components, respectively, and $t_{\mathrm{f}}$ and $t_{\mathrm{s}}$ are the respective decay time constants.

Spontaneous events were recorded over a period of at least $5 \mathrm{~min}$. Statistical analysis was performed with Prism software. All datasets were described using the mean \pm SEM. The statistical differences between cell groups were compared with the nonparametric Mann-Whitney $U$ test.

\section{Results}

\section{GABAergic synapses onto olfactory bulb granule cells}

In the $\mathrm{OB}, \alpha 2-\mathrm{GABA}_{\mathrm{A}}$ Rs are expressed by GCs and PGCs only (Laurie et al., 1992; Fritschy and Mohler, 1995; Pirker et al., 2000; Panzanelli et al., 2007). Accordingly, immunofluorescence labeling for the $\alpha 2$ subunit reveals punctate immunoreactivity throughout the $\mathrm{OB}$, suggesting that both GCs and PGCs receive GABAergic synapses along their dendrites (Fig. 1A). To demonstrate this, we used GAD67-GFP mice (Tamamaki et al., 2003), in which GCs, but not short-axon cells, are strongly labeled with eGFP. This selective distribution was verified by double labeling with an antibody against the $\mathrm{GABA}_{\mathrm{A}} \mathrm{R} \alpha 1$ subunit, a marker of a major subpopulation of deep short axon cells (Eyre et al., 2009) (supplemental Fig. 1, available at www.jneurosci.org as supplemental material). Next, we used double immunofluorescence to visualize the localization of the $\alpha 2$ subunit and gephyrin, a marker of inhibitory postsynaptic sites, in the GCL and EPL (Fig. $1 B-D$ ). A distinct labeling of $\alpha 2$ subunit-positive clusters colocalized with gephyrin was observed on eGFP-positive dendrites (Fig. $1 C, D$ ), suggestive of GABAergic synapses onto GCs. To confirm these observations ultrastructurally, we performed dual-labeling immunoelectron microscopy in OB sections of GAD67-GFP mice with antibodies against eGFP (revealed by immunoperoxidase) and gephyrin (detected with silver-intensified nanogold particles). We observed gephyrin labeling at postsynaptic sites of eGFP-positive dendrites in the EPL (Fig. 1E), GCL (Fig. 1F), and mitral cell layer (Fig. 1G). Presynaptic terminals apposed to gephyrin were negative for eGFP, suggesting that they may belong to short-axon cell terminals. Together, these results indicate that GC dendrites receive GABAergic synapses containing $\alpha 2-\mathrm{GABA}_{\mathrm{A}}$ receptors along with gephyrin in the postsynaptic density.

To quantify the density of synapses containing $\alpha 2-\mathrm{GABA}_{\mathrm{A}}$ receptors in the different layers of the $\mathrm{OB}$, the number of $\alpha 2$ subunit- and gephyrin-positive clusters was assessed in sections 
from wild-type mice $(n=4)$ processed for double immunofluorescence. The density of $\alpha 2$ subunit-positive clusters was $38 \pm 8$ per $1000 \mu \mathrm{m}^{2}$ in the GL, $51 \pm 11$ in the outer EPL, $42 \pm 10$ in the inner EPL, $61 \pm$ 19 in the IPL, and $48 \pm 13$ in the GCL. These figures represent $25 \%$ of the total number of gephyrin clusters in the GL, $7 \%$ in the EPL, and $70 \%$ in the GCL, in line with the predominance of GABAergic input mediated by other $\mathrm{GABA}_{\mathrm{A}} \mathrm{R}$ subtypes in M/T cells in the EPL and GL.

Early morphological and functional differentiation of newborn granule cells To investigate the maturation and synaptic integration of newborn GCs, we injected a lentivirus encoding PGK-eGFP into the RMS of 8-week-old mice (Fig. $2 A, B)$. eGFP-positive GCs were analyzed between 3 and 7 dpi to investigate the initial steps of synaptogenesis. At $3 \mathrm{dpi}$, only a few eGFP-positive cells were seen in the GCL (Fig. 2C, $C^{\prime}$ ). These cells typically had basal dendrites and extended an apical dendrite radially toward the EPL. Double labeling with antibodies against doublecortin confirmed that all eGFPpositive cells are newborn neurons (data not shown). At $5 \mathrm{dpi}$ (Fig. $2 D, D^{\prime}$ ), the number of eGFP-positive cells had increased. They were morphologically more developed, with apical dendrites penetrating into the EPL and carrying secondary branches. Between 5 and $7 \mathrm{dpi}$, the number of eGFP-positive cells increased even further, and their morphological development proceeded rapidly, as seen best by the development of their apical dendrite, which carried spine-like protrusions and filopodia. At 7 dpi, eGFP-positive cells had spiny dendrites with a morphology resembling those of mature GC (Fig. 2E), although they still were doublecortin-positive (data not shown). At this stage, eGFP-positive cells typically extended an extensively branched apical dendrite into the EPL (Fig. 2 $E^{\prime}$ ). Morphologically, such eGFP-positive cells corresponded to class 5 neurons described in previous studies (Carleton et al., 2003). These results indicated that, although migration of eGFP-positive newborn GCs proceeds over several days within the RMS, their morphological differentiation is rapid once they get off the migratory stream to populate the $\mathrm{OB}$.

Next, we used whole-cell patch-clamp recordings to determine the functional characteristics of newborn GCs compared with eGFP-negative GCs in acute slices of virus-injected mice (Fig. $2 F-H$ ). As expected, if eGFP-positive cells mature with time after injection, we found that the input membrane resistance of adult-born GCs was particularly high at $3 \mathrm{dpi}$ and decreased to values similar to those of eGFP-negative GCs at 7 dpi (Fig. 2G). Conversely, the amplitude of voltage-dependent sodium currents, measured in the presence of intracellular cesium (i.e., potassium current blocker), increased significantly between 3 and 7 dpi (Fig. $2 H)$. These currents were detected in all sampled cells $(n=47)$. These results suggested that functional maturation goes in line with morphological differentiation during this early time window of 4 days.

\section{Early synaptic inputs onto newborn granule cells}

Next, we used focal electrical stimulations in the GCL (Fig. 3A) to characterize the synaptic inputs impinging onto newborn GCs. Surprisingly, we found that GCs at $3 \mathrm{dpi}$ already receive functional GABAergic and glutamatergic synapses (Fig. 3B-D), although they appear morphologically and physiologically immature (compare Figs. 2, 3E).

To determine the subcellular localization of GABAergic and glutamatergic synapses, sections from virus-injected mice were processed for immunofluorescence with various presynaptic and postsynaptic markers (GABAergic synapses: VGAT, GABA $\mathrm{R} \alpha 2$ subunit, gephyrin; glutamatergic synapses: vGluT1, PSD-95), combined with immunostaining for eGFP to enhance the sensitivity of detection of fine dendritic processes in young immature GCs. Consistent with our electrophysiological data, we observed clusters of gephyrin or $\alpha 2$ subunit localized within basal and apical dendrites and cell bodies (Fig. $3 F, F^{\prime}$ ) of eGFP-positive cells. Similarly, clusters of PSD-95 colocalized with eGFP (Fig. $3 G, G^{\prime}$ ) were also observed in eGFP-positive cells, suggesting the presence of both GABAergic and glutamatergic postsynaptic sites 


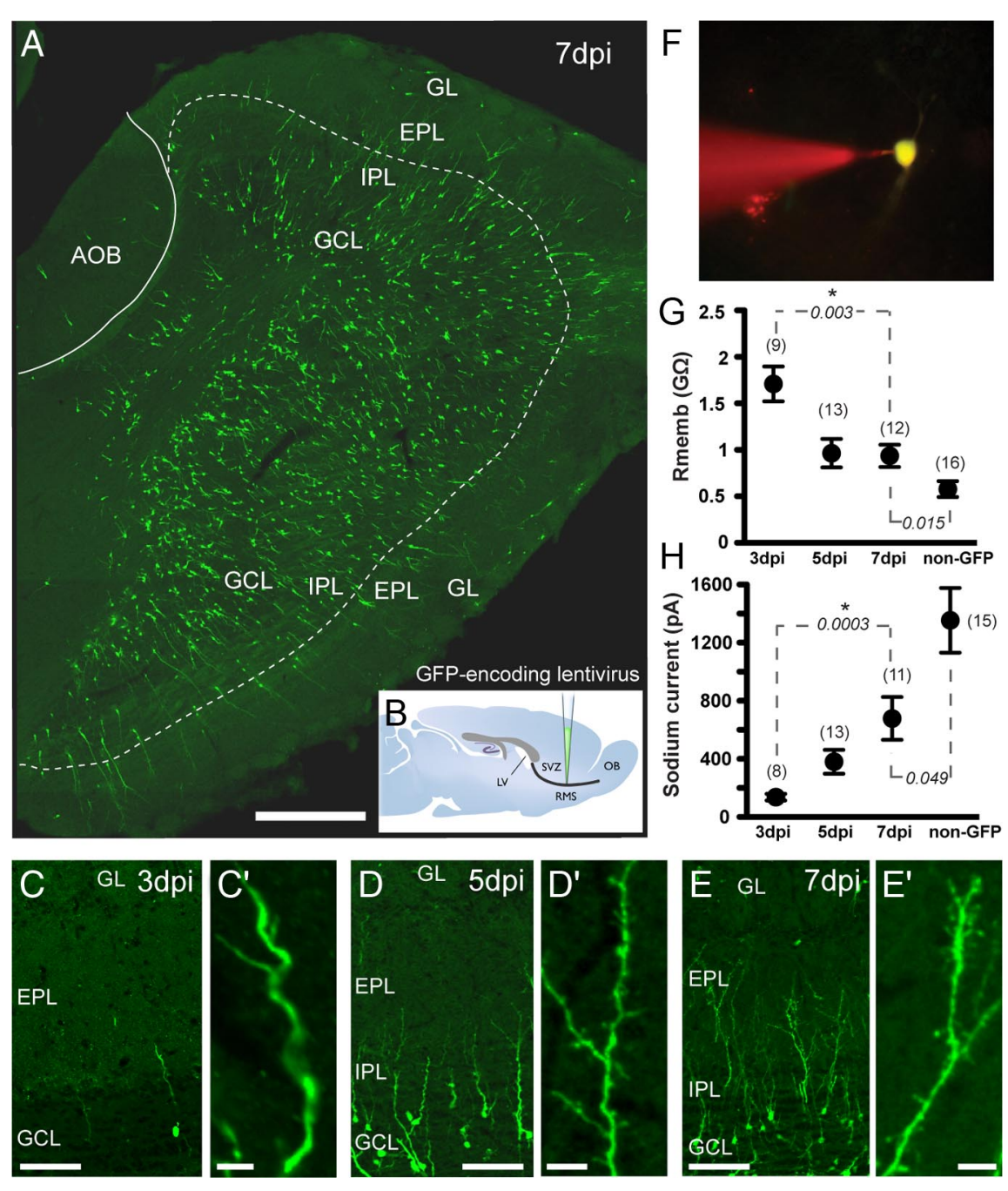

Figure 2. Early differentiation of newborn granule cells. $\boldsymbol{A}$, Low-magnification photomicrograph depicting the distribution and morphology of eGFP-positive newborn GCs in adult mouse OB at $7 \mathrm{dpi}$, as detected by combined eGFP and immunofluorescence with antibodies against GFP. The dotted line indicates the mitral cell layer; the continuous line surrounds the accessory olfactory bulb (AOB). Scale bar, $200 \mu \mathrm{m}$. B, Schematic diagram of our experimental approach to label adult born GCs by stereotaxic injection of a lentivirus encoding eGFP into the RMS. $\boldsymbol{C}-\boldsymbol{E}$, Morphology of typical eGFP-positive GCs between 3 and 7 dpi; note the rapid growth of dendrites, becoming more branched and carrying numerous spine-like protrusions and filopodia. Scale bars: $\boldsymbol{C}, \boldsymbol{D}, \boldsymbol{E}, 50$ $\mu \mathrm{m} ; \boldsymbol{C}^{\prime}, \boldsymbol{D}^{\prime}, \boldsymbol{E}^{\prime}, 5 \mu \mathrm{m}$. $\boldsymbol{F}$, Example of an eGFP-positive GC filled with rhodamine during the patch-clamp recording. $\boldsymbol{G}$, Graph of the mean \pm SEM membrane input resistance of eGFP-positive neurons $(3,5$, or 7 dpi) compared with "preexisting" GCS (non-GFP). $\boldsymbol{H}$, Graph of the mean \pm SEM voltage-dependent sodium current amplitude of eGFP-positive neurons increased rapidly toward those of preexisting cells. The number of cells in each group is shown in brackets. The Mann-Whitney $p$ values are shown in italics.

already at 3 dpi (see next section for quantification). We also observed an extensive apposition of VGAT and gephyrin clusters (supplemental Fig. 2, available at www.jneurosci.org as supplemental material) and of VGLUT1 and PSD-95 (supplemental Fig. 3 , available at www.jneurosci.org as supplemental material) on eGFP-positive dendrites and cell bodies at 3-4 dpi. Together, these results indicate the presence of functional synapses on the soma and proximal domain of dendrites of newborn GCs within a few hours after entering the GCL.

\section{Maturation of synaptic inputs onto newborn granule cells}

During brain ontogenesis, functional properties of $\mathrm{GABA}_{\mathrm{A}} \mathrm{R}$ and their subunit composition are known to change (Fritschy et al., 1994), possibly reflecting adaptations during maturation of neuronal circuits. Therefore, we investigated in more detail whether the properties of GABAergic synapses change during the matu- ration of adult-born neurons in the GCL (Fig. 4). Using whole-cell patch-clamp recordings, we found that the amplitude and the success rate of evoked GABAergic postsynaptic currents increased significantly from 3 to 7 dpi. Similarly, the frequency of spontaneous events increased, but, unlike evoked currents, the amplitude of spontaneous events remained constant (Fig. 4A1-A4). Together, these results indicate that the number of functional GABAergic synaptic contacts received by newborn GCs increased rapidly between 3 and 7 dpi. Of course, these observations do not rule out potential contributions of age-dependent change in the excitability of the presynaptic neurons. The amplitude and success rate of evoked GABA currents, as well as the frequency of spontaneous events, were not different in eGFP-positive and eGFP-negative GCs recorded in slices taken at $7 \mathrm{dpi}$, underscoring the rapid maturation of functional GABAergic synaptic contacts in newborn GCs. Analysis of paired-pulse ratios revealed values slightly $<1$, which did not change significantly between the different groups (Fig. 4B1,B2). This result indicates that the probability of presynaptic release of GABA did not change in relation to the maturity of target cells. Finally, analysis of the kinetics of evoked responses showed no significant difference in rise time between newborn neurons and preexisting ones (Fig. 4C1,C2). This result implies that $\mathrm{GABA}_{\mathrm{A}} \mathrm{R}$ subtypes and their distribution at synaptic inputs are homogeneous in newborn and preexisting GCs. The first phase (Tau 1) of the decay time appeared to be faster only in the 3 dpi group (Fig. 4C3), probably resulting from more compact GC dendrites.

To determine on which subcellular compartment of newborn GCs synaptic inputs are established, and to assess the relative proportion of glutamatergic and GABAergic inputs, we quantified the density of PSD-95 and gephyrin clusters on the soma, basal dendrites, and apical dendrites within the GCL at 3, 5, and 7 dpi (Fig. 5A-F, Table 1). On the soma, a selective increase in the density of PSD-95 clusters, as quantified as a function of the cell perimeter, was observed between 3 and 7 dpi (Fig. 5G, Table 1). Two-way ANOVA analysis revealed a main effect of time $\left(F_{(2,210)}=5.390\right.$; $p=0.0052)$ and a significant interaction between time and cluster type $\left(F_{(2,210)}=3.599 ; p=0.0291\right)$, reflecting the increasing density of PSD-95, but not gephyrin-positive clusters. Thus, at 3 $\mathrm{dpi}$, the fraction of gephyrin clusters was significantly higher, but at 7 dpi, PSD-95 clusters were predominant, suggesting a slight delay in the formation of glutamatergic synapses on newborn GCs. In basal dendrites (Fig. 5H, Table 1), two-way ANOVA analysis only revealed a main effect of the type of clusters $\left(F_{(1,135)}=\right.$ $6.902 ; p=0.0096)$ because of the larger fraction of PSD-95 clusters, in particular at 7 dpi. Finally, in apical dendrites (Fig. 5I, 
Table 1), a significant effect of time was found $\left(F_{(2,239)}=4.721 ; p=0.0098\right)$ because of a marked increase in density of PSD-95 between 3 and 7 dpi. Together, these results show that the total synaptic coverage of newborn GCs increases markedly between 3 and 7 dpi because of rapid growth of their dendrites. Although they initially received a similar fraction of both types of synapses, as seen at $3 \mathrm{dpi}$, a predominance of glutamatergic over GABAergic synapses was established at 7 dpi, suggesting that the former are established in two successive waves in the GCL. However, no evidence was found, for a proximal-to-distal gradient of synapse formation from basal to apical dendrites.

\section{GABAergic input on granule cell spine-like protrusions}

VGAT immunofluorescence staining was used to confirm the formation of GABAergic synapses onto newborn GCs. However, this analysis was complicated by the fact that VGAT was present not only in terminals innervating newborn GCs, but also within GC themselves, notably at the level of reciprocal synapses formed with $\mathrm{M} / \mathrm{T}$ cell dendrites. Presynaptic input onto GCs was therefore expected to be evidenced by VGAT-positive puncta localized outside of, but in close contact with, eGFPpositive dendrites. In the IPL, just below the mitral cells, the dendrites of newborn GCs formed spine-like protrusions, first seen at 3 dpi. Double staining for VGAT and eGFP revealed that VGAT clusters were either completely embedded within eGFP-positive dendrites or in close apposition to eGFP-positive dendrites and spine-like protrusions (Fig. 6; supplemental Fig. 2, available at www.jneurosci.org as supplemental material), suggesting formation of GABAergic synapses on dendritic shafts and spines. This feature was most evident up to $5 \mathrm{dpi}$ in the IPL, whereas most VGAT puncta rather were apposed to dendritic shafts at 6 and $7 \mathrm{dpi}$. To confirm the possibility that some GABAergic synapses might form, at least transiently, on GC spines in the IPL, we analyzed triple-staining experiments for the $\alpha 2$ subunit, gephyrin, and eGFP. Highresolution imaging confirmed the presence of $\alpha 2$ /gephyrin clusters located inside of eGFP-positive dendrites and spine-like protrusions (Fig. 6D) at 4 and $5 \mathrm{dpi}$. As seen in mature GCs, $\alpha 2$ subunit-positive clusters typically were colabeled for gephyrin, arguing for the presence of a GABAergic postsynaptic site. At 6 and $7 \mathrm{dpi}$, in line with the distribution of VGAT puncta, most $\alpha 2$ subunit/gephyrin clusters were observed in dendritic shafts (data not shown).

Similar features were observed in the EPL, where GCs also receive inhibitory synapses from short-axon cells (Eyre et al., 2008). Using colocalization of $\alpha 2$ subunit and gephyrin clusters,

$\mathrm{B}$

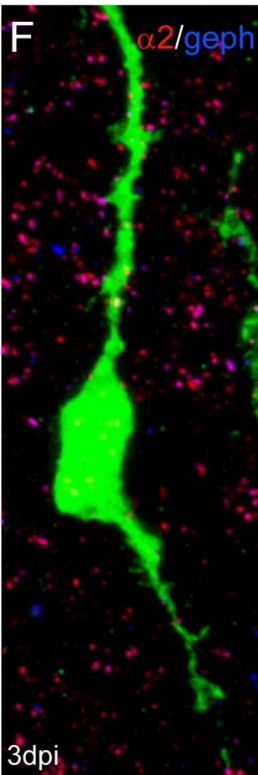

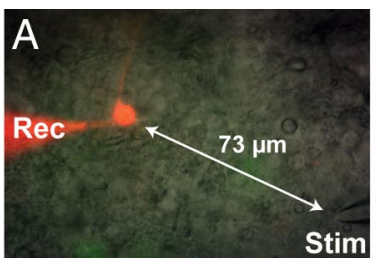
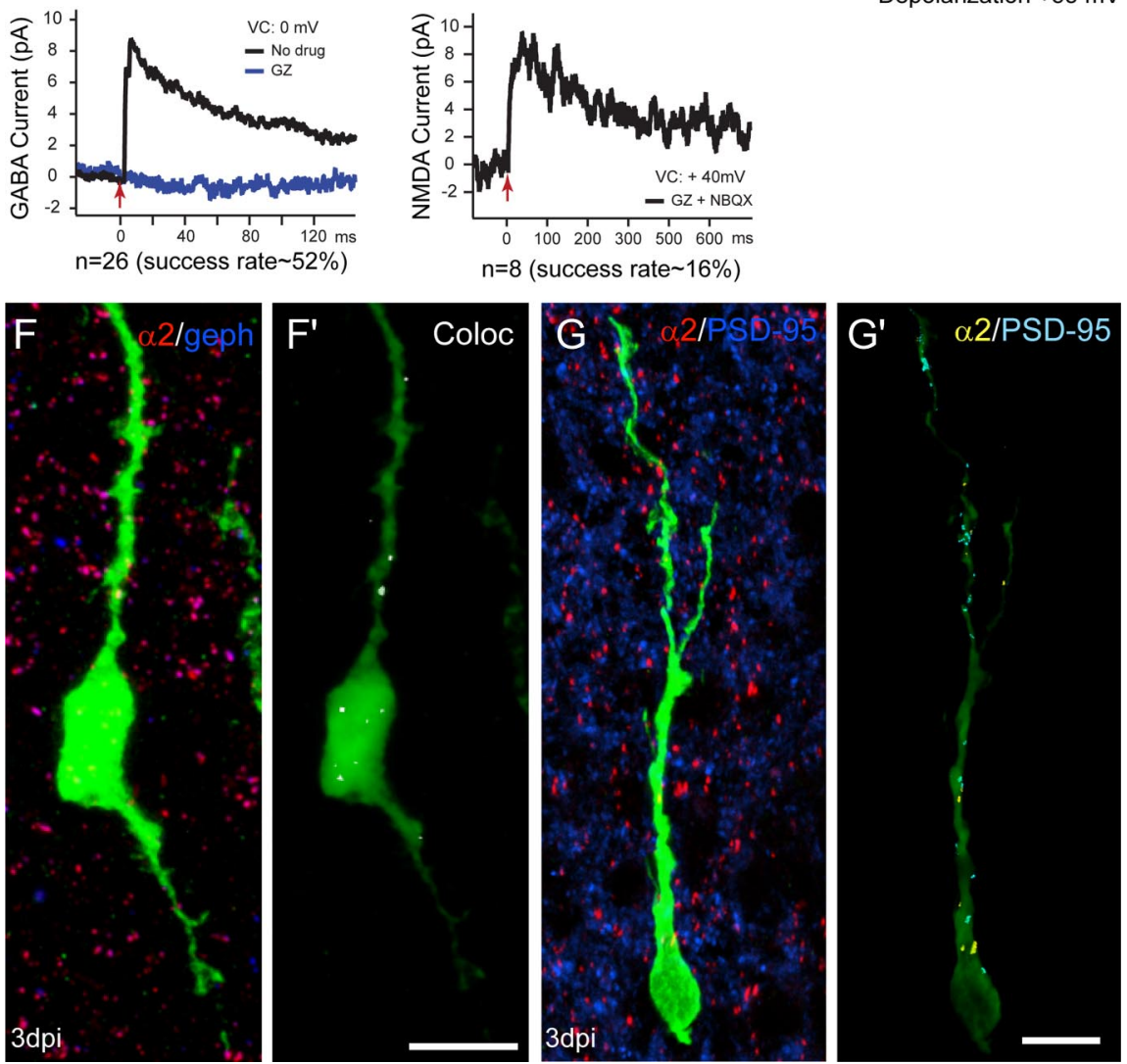

Figure 3. Early synaptic inputs onto newborn granule cells. $\boldsymbol{A}$, Photomicrograph depicting a whole-cell recording of a newborn GC, with the recording electrode (Rec) implanted on a cell filled with rhodamine. The stimulating electrode (Stim) appears on the picture in a representative position. $\boldsymbol{B}$, Voltage-clamp recordings at the reversal potential of AMPA- and NMDA-mediated currents $(0 \mathrm{mV})$ in drug-free ACSF permitted to reveal evoked GABA currents (black trace: average of 26 nonfailure traces; success rate, $52 \%)$, which disappeared in the presence of gabazine (GZ), a GABA $\mathrm{R}$ antagonist (blue trace: average of 26 traces; success rate, 0\%). C, Voltage-clamp recordings at - $70 \mathrm{mV}$ in ACSF plus GZ showing evoked AMPA-mediated currents (black trace: average of 15 nonfailure traces; success rate, 30\%), which disappeared when the AMPA receptor antagonist NBQX was added to the perfusion (blue trace: average of 15 traces; success rate, 0\%). D, Voltage-clamp recordings at $+40 \mathrm{mV}$ in ACSF plus GZ plus NBQX showing evoked NMDA-mediated currents (black trace: average of 8 nonfailure traces; success rate, 16\%). $\boldsymbol{E}$, Voltage-dependent sodium current triggered by a depolarizing pulse of $55 \mathrm{mV} . \boldsymbol{F}, \mathbf{G}$, Double immunofluorescence staining for $\mathrm{GABA}_{\mathrm{A}} \mathrm{R} \alpha 2$ subunit (red) and PSD-95 or gephyrin (blue), depicting their clustered distribution on the soma, apical dendrites, and basal dendrites of eGFPpositive GC at $3 \mathrm{dpi}$; both pictures are maximum intensity projections of confocal images ( $\boldsymbol{F}, 16$ sections spaced $0.5 \mu \mathrm{m} ; \boldsymbol{G}, 11$ sections spaced $0.35 \mu \mathrm{m}) . \boldsymbol{F}^{\prime}, \boldsymbol{G}^{\prime}$, The presence of presumptive postsynaptic sites in these two newborn $\mathrm{GCs}$ is inferred from the

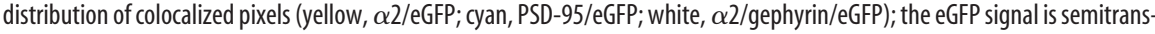
parent for clarity. Scale bars, $5 \mu \mathrm{m}$.

putative synapses made by short-axon cells on newborn GCs were readily found at $5 \mathrm{dpi}$ on eGFP-positive dendritic shafts (Fig. 6E), shortly after they had penetrated the EPL (Fig. 2D); they were observed also on spine-like protrusions (Fig. $6 E$ ), similar to those seen in the IPL. With electron microscopy (see below), we confirmed the presence of gephyrin located inside of spine structures at $7 \mathrm{dpi}$. Thus, eGFP-positive dendrites received GABAergic input as soon as they reached the EPL, similar to the rapid formation of GABAergic synapses in the GCL, and spinelike protrusions might serve as a transient postsynaptic target. 
A1

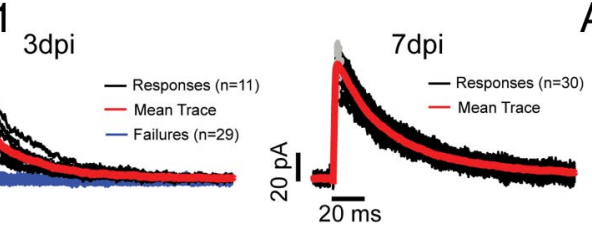

A3

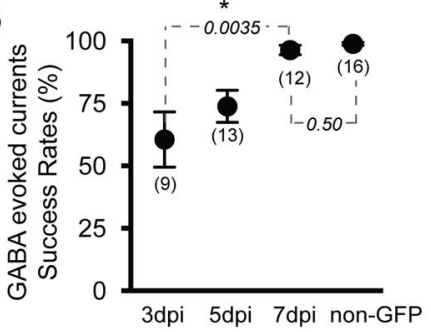

B1
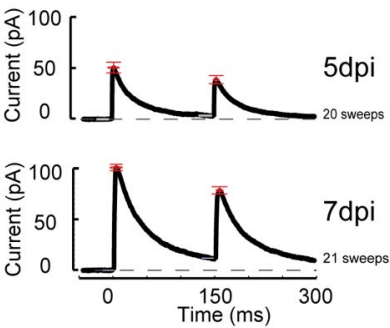

C2

C1
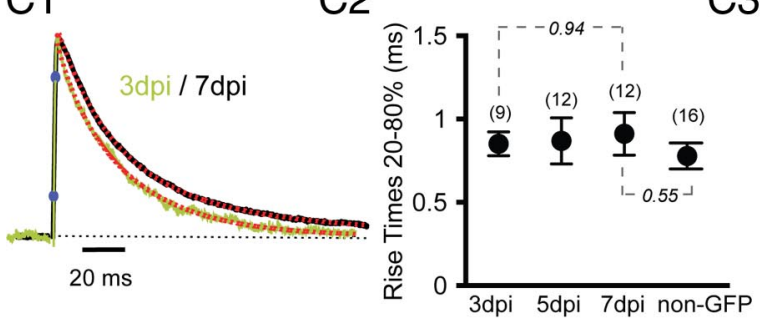

A4

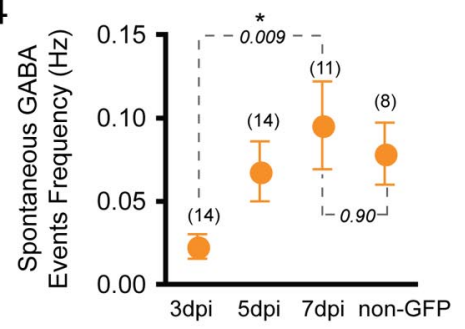

B2

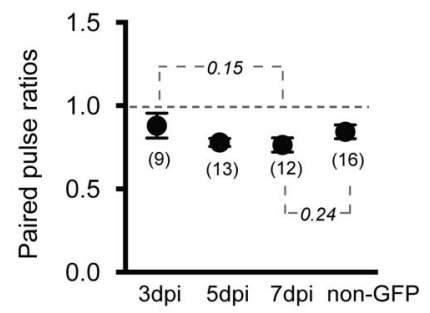

and distal inputs were identical (EPL, $0.85 \pm 0.04, n=7$; GCL, $0.87 \pm 0.07, n=$ 14 ; Mann-Whitney, $p=0.79$ ), suggesting that the two segregated GABAergic pathways share similar presynaptic features. To determine the precise onset of functional GABAergic contacts impinging onto proximal or distal portion of the apical dendrite, in the subset of cells responding to EPL stimulation we calculated the proportion of responses that were blocked by antagonist application either in the GCL or in the EPL (Fig. 7C). We found that functional GABAergic synapses in the EPL appeared as soon as the apical dendrites reached the EPL ( 5-7 dpi). Significant differences in functional properties of IPSCs (rise and decay time constants, amplitude, success rate) were observed between proximal and distal synapses formed on the same GC, whereas the paired-pulse ratios were identical (supplemental Fig. 4, available at www. jneurosci.org as supplemental material).

\section{Formation of reciprocal,}

dendrodendritic synapses in the EPL

Next, to study the formation of reciprocal synapses in the EPL, we considered that, at these sites, gephyrin is clustered in $\mathrm{M} / \mathrm{T}$ cell dendrites, facing the release site formed by the GC spine. In addition, these synapses contain $\alpha 1$ - and $\alpha 3-\mathrm{GABA}_{\mathrm{A}} \mathrm{R}$ along with gephyrin (Panzanelli et al., 2005). In turn, M/T cells form presynaptic release sites immunopositive for vGluT1, whereas PSD-95 marks the postsynaptic density in the GC spine. Using triple immunofluorescence with a mixture of antibodies against the $\alpha 1 / \alpha 3$ subunit, PSD-95, and eGFP, we identified clusters of $\alpha 1$ / $\alpha 3$ subunit immunoreactivity closely apposed to PSD-95 clusters in eGFP-positive dendrites at 4-5 dpi and in spine-like protrusions at 5 and 7 dpi (Fig. $8 A-C$ ). We also observed on eGFP-positive dendrites PSD-95 clusters that were not apposed to $\alpha 1 / \alpha 3$ clusters and vice versa (Fig. $8 A-C$ ). To rule out that these observations were

To physiologically differentiate proximal versus distal GABAergic synaptic inputs and confirm the presence of functional GABAergic synapses onto newborn GCs in the EPL, we applied focal electrical stimulations in the GCL or the EPL while puffing subsequently the $\mathrm{GABA}_{\mathrm{A}} \mathrm{R}$ antagonist SR-95531 to characterize the evoked responses in both proximal and distal domains of the apical dendrite (Fig. 7A1). Consistent with a more distant localization of EPL inputs compared with GCL inputs, when recording at the GC soma, the amplitude and kinetics of GABAergic postsynaptic currents (IPSCs) evoked in the EPL were significantly smaller (Fig. 7A2) and slower (mean \pm SEM, rise time $20-80 \%, 2670 \pm 390 \mu$ s; decay time $\tau 1,43 \pm 7 ; n=7$ ) than those from GCL inputs (mean \pm SEM, rise time $20-80 \%, 730 \pm 100$ $\mu \mathrm{s}$; decay time $\tau 1,22 \pm 3 \mathrm{~ms} ; n=14$; Mann-Whitney, $p=0.0005$ and $p=0.002$, respectively). The paired-pulse ratios of proximal artifacts from insufficient resolution of confocal microscopy, examination of the EPL was performed at $21 \mathrm{dpi}$ and revealed the systematic presence of $\alpha 1 / \alpha 3$ and PSD-95 immunolabeling on eGFP-positive dendritic spines (Fig. $8 D$ ).

To quantify these observations on images collected at 4,5 , and $7 \mathrm{dpi}$, we considered separately clusters formed on dendrites and on spines. In dendrites, PSD-95 clusters "alone" (without $\alpha 1 / \alpha 3$ subunit) gradually decreased over time, whereas the density of PSD-95 clusters closely apposed to $\alpha 1 / \alpha 3$ subunit-positive clusters increased (Fig. $8 E$ ). In comparison, the density of the $\alpha 1 / \alpha 3$ clusters not apposed to a PSD-95 decreased over time and only few clusters containing the $\alpha 1 / \alpha 3$ subunit not apposed to a PSD-95 cluster were seen at 7 dpi (Table 2, top). A two-way ANOVA revealed a main effect of different types of clusters $(\alpha 1 / \alpha 3$, PSD-95, apposed $)\left(F_{(2,267)}=14.95 ; p<0.0001\right)$ but 
PSD-95

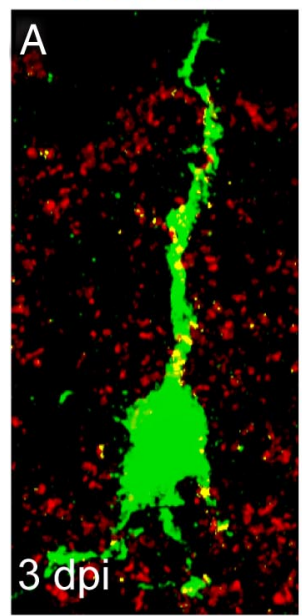

G

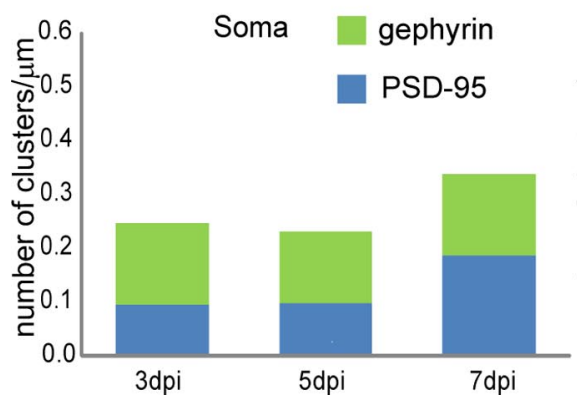

PSD-95

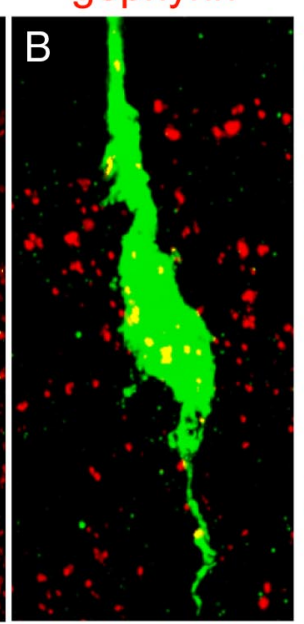

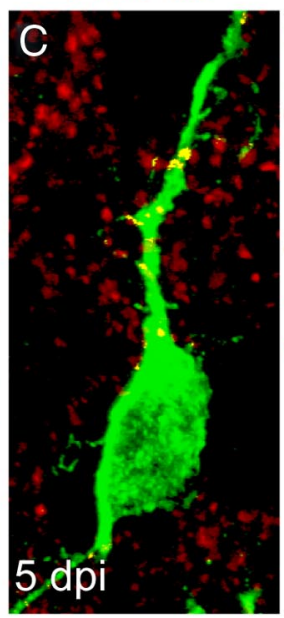

$\mathrm{H}$

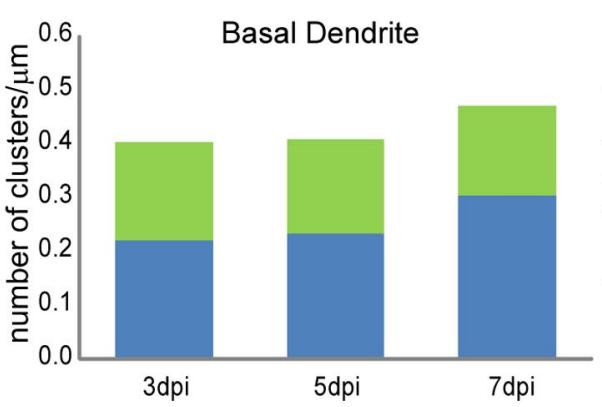

gephyrin

PSD-95

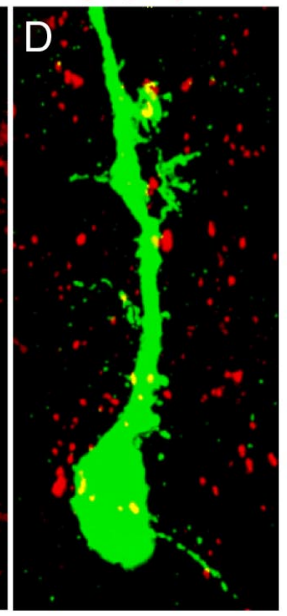

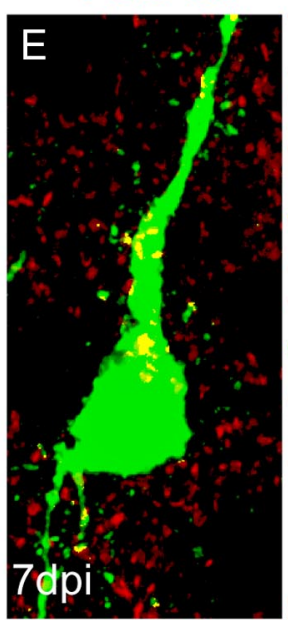

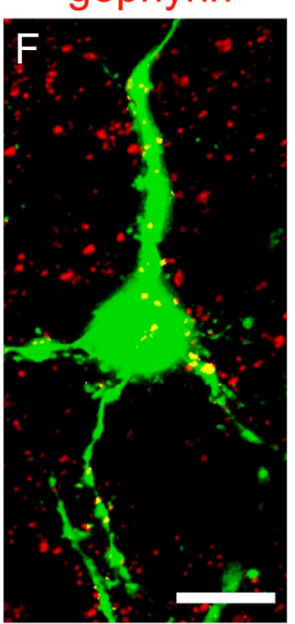

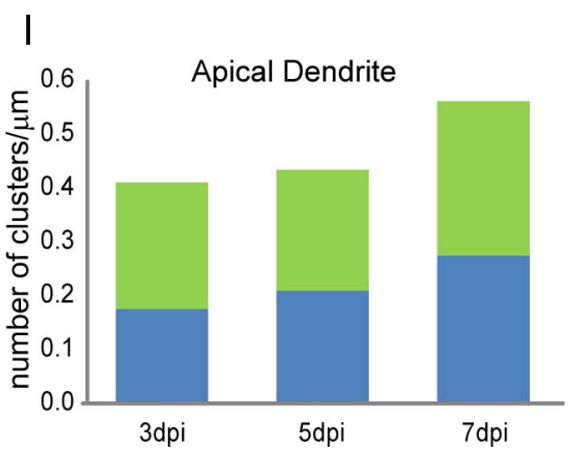

Figure 5. Quantification of synaptic inputs formed on newborn granule cells. $\boldsymbol{A}-\boldsymbol{F}$, Representative images from confocal microscopy depicting the presence of PSD-95 clusters $(\boldsymbol{A}, \boldsymbol{C}, \boldsymbol{E})$ and gephyrin clusters $(\boldsymbol{B}, \boldsymbol{D}, \boldsymbol{F})$ colocalized with eGFP (yellow) at 3,5, and $7 \mathrm{dpi}$, respectively, in the GCL. All pictures are maximum intensity projections of confocal images (10 - 16 sections spaced 0.35 $\mu \mathrm{m})$. Scale bar, $10 \mu \mathrm{m}$. G-I, Quantification of PSD-95 and gephyrin clusters colocalized with eGFP on the soma, basal dendrites, and apical dendrites at 3, 5, and 7 dpi (for mean \pm SEM, see supplemental Table 1, available at www.jneurosci.org as supplemental material). $\mathbf{G}, 0$ n the soma, the density of PSD-95 clusters increased significantly between 3 and 5 versus 7 dpi (Bonferroni's post test, $p<0.01$ ), and at $7 \mathrm{dpi}$ the density of PSD-95 clusters was significantly higher than gephyrin-positive clusters (Bonferroni's post test, $p<0.05$ ). $\boldsymbol{H}, 0 \mathrm{n}$ basal dendrites, as well, PSD-95-positive clusters were significantly more numerous than gephyrin clusters (Bonferroni's post test, $p<0.05$ ). I, On apical dendrites, the density of PSD-95 clusters increased significantly between 3 and 7 dpi (Bonferroni's post test, $p<0.05$ ).

Table 1. Density of PSD-95 and gephyrin clusters on newborn GCs in the GCL

\begin{tabular}{|c|c|c|c|c|c|c|}
\hline & \multicolumn{2}{|l|}{ Soma } & \multicolumn{2}{|c|}{ Basal dendrites } & \multicolumn{2}{|l|}{ Apical dendrites } \\
\hline & PSD-95 & Gephyrin & PSD-95 & Gephyrin & PSD-95 & Gephyrin \\
\hline $3 \mathrm{dpi}$ & $0.09 \pm 0.02$ & $0.15 \pm 0.01$ & $0.22 \pm 0.05$ & $0.18 \pm 0.02$ & $0.18 \pm 0.02$ & $0.23 \pm 0.02$ \\
\hline $5 \mathrm{dpi}$ & $0.10 \pm 0.02$ & $0.13 \pm 0.01$ & $0.23 \pm 0.04$ & $0.17 \pm 0.04$ & $0.21 \pm 0.03$ & $0.22 \pm 0.02$ \\
\hline $7 \mathrm{dpi}$ & $0.18 \pm 0.03^{* 0}$ & $0.15 \pm 0.02$ & $0.30 \pm 0.04$ & $0.17 \pm 0.03$ & $0.28 \pm 0.02^{*}$ & $0.29 \pm 0.03$ \\
\hline
\end{tabular}

The density of clusters is the mean \pm SD cluster per micrometer dendrite length or soma perimeter. Note the delayed increase of PSD-95 clusters on the soma and apical dendrites. The symbols indicate the results of Bonferroni's post ho tests (for main statistical analysis, see Results).

*7 dpi different from $3 \mathrm{dpi}, p<0.01 ;{ }^{\circ} 7 \mathrm{dpi}$ different from $5 \mathrm{dpi}, p<0.05$.

no effect related to the age of the cells $\left(F_{(2,267)}=1.875 ; p=\right.$ $0.1553)$. The interaction between cluster type and time was significant $\left(F_{(4,267)}=9.034 ; p<0.0001\right)$ (Table 2, top). These findings indicate that formation of reciprocal synapses takes place at all ages analyzed, with a predominance of contacts containing only PSD-95 clusters rather than only $\alpha 1$ plus $\alpha 3$ subunit clusters.

Before quantifying clusters on spines, we assessed the total spine density on dendrites in EPL and observed a significant increase between 4 and 7 dpi (Fig. 8 F; Table 2, bottom). We also observed a significant increase of PSD-95 clusters apposed to $\alpha 1 / \alpha 3$ subunit clusters at 5 and 7 dpi versus 4 dpi (Fig. $8 F$ ). However, because of the low number of spines at this stage, we observed more PSD-95 clusters apposed to $\alpha 1 / \alpha 3$ subunit clusters in eGFP-labeled dendrites than in spines. A two-way
ANOVA revealed a main effect of different types of clusters $(\alpha 1 /$ $\alpha 3$, PSD-95, apposed, nonlabeled spine) $\left(F_{(3,356)}=26.24 ; p<\right.$ $0.0001)$ and of time $\left(F_{(2,356)}=8.393 ; p=0.0003\right)$. The interaction between cluster type and time was significant, as well $\left(F_{(6,356)}=3.544 ; p=0.002\right)$ (Table 2 , bottom), reflecting the fact PSD-95 clusters apposed to $\alpha 1 / \alpha 3$ subunit gradually become predominant. Accordingly, post hoc analysis confirmed the gradual increase of PSD-95 clusters apposed to $\alpha 1 / \alpha 3$ subunit at the expense of "single labeled" clusters (Fig. 8 F; Table 2, bottom), likely reflecting the maturation of reciprocal synapses on GC spines. These results suggest that reciprocal synapses form on dendrites before spine formation and that the glutamatergic component might be assembled shortly before the GABAergic component. Therefore, M/T cells might play a leading role in establishing reciprocal synapses with newborn GCs. 

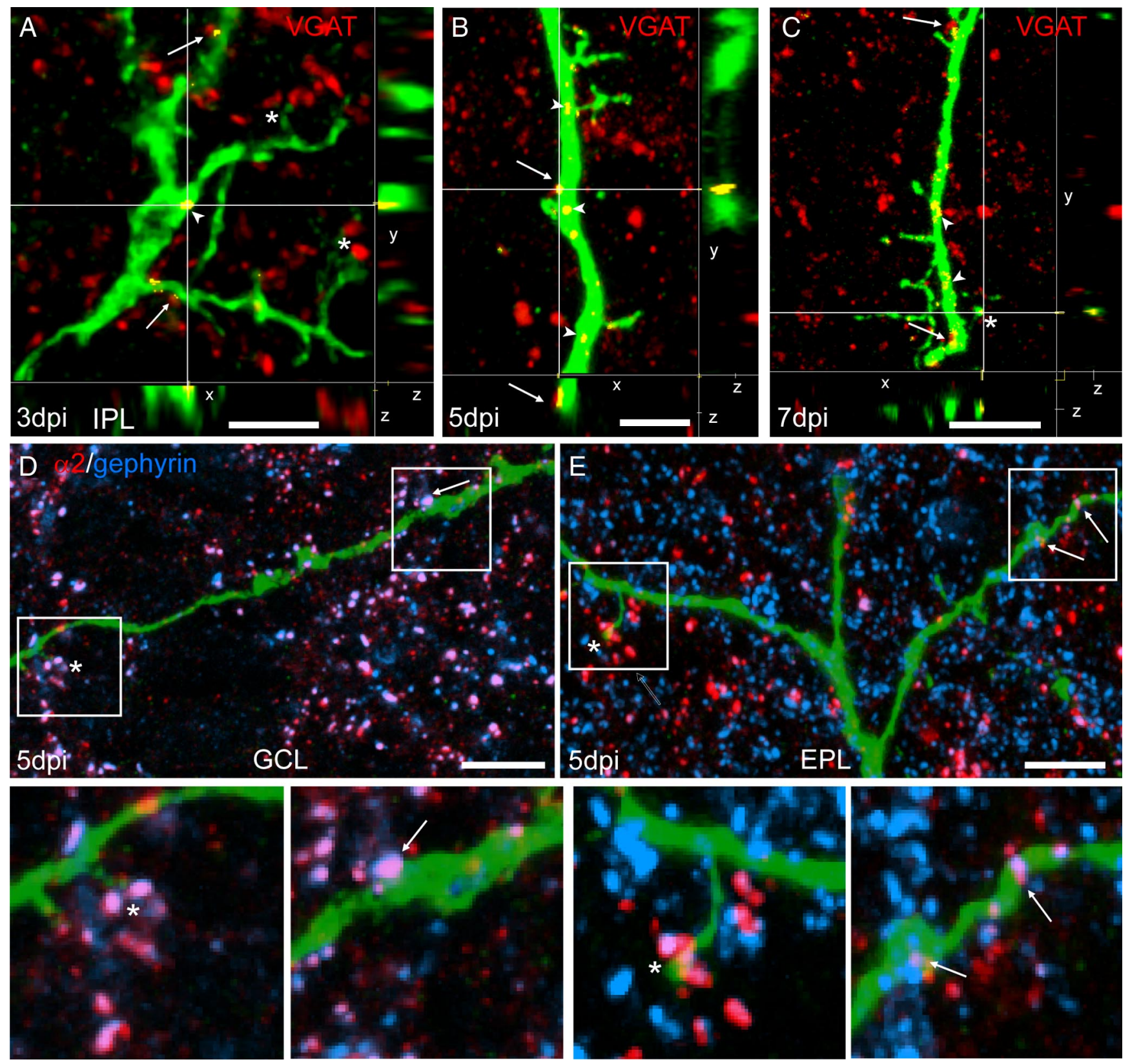

Figure 6. GABAergic input on granule cells spines. A-C, Distinction of VGAT-positive clusters inside and apposed to eGFP-positive dendrites and spine-like structures in the GCL at 3,5 , and 7 dpi. The arrows point to VGAT clusters apposed to dendrites, representing putative synaptic input; the arrowheads indicate VGAT clusters inside eGFP-positive dendrites; these VGAT proteins are probably transported toward the EPL to form reciprocal synapses. Note that, at 3 and 5 dpi, some VGAT clusters are formed onto eGFP-positive spines $\left({ }^{*}\right)$. Images are shown as three-dimensional projections in the three Cartesian planes, and sites of colocalization are marked in yellow. $\mathbf{D}, \boldsymbol{E}$, Double immunofluorescence staining for gephyrin (blue) and the $\alpha 2$ subunit (red) colocalized (magenta) in clusters inside eGFP-positive spine-like structures and dendritic shafts in GCL and in the EPL, suggestive of GABAergic input at 5 dpi. The framed areas are enlarged to better illustrate clusters in spines $\left(^{*}\right)$ and shafts (arrows). The pictures are maximum intensity projections of confocal sections (11-15 layers spaced by $\left.0.4 \mu \mathrm{m}\right)$. Scale bars: $\boldsymbol{A}, 5 \mu \mathrm{m} ; \boldsymbol{B}, \boldsymbol{C}, 3 \mu \mathrm{m} ; \boldsymbol{D}, \boldsymbol{E}, 5 \mu \mathrm{m}$.

\section{Immunoelectron microscopy analysis}

To confirm ultrastructurally the presence of synapses on newborn GCs in the adult OB, sections from 7 dpi mice were processed for dual preembedding immunolabeling for eGFP (immunoperoxidase) and gephyrin (secondary antibody coupled to nanogold particles) and analyzed by electron microscopy. At this stage, we expected from the immunofluorescence data to find fully differentiated reciprocal synapses involving newborn GCs. As shown in Figure 9, eGFP-positive synaptic profiles with the typical morphology of GC spine profile were readily seen in the EPL. A systematic survey of ultrathin sections revealed the existence of GABAergic synapses (marked with gephyrin immunore- activity) formed onto mitral cell profiles by eGFP-positive spines (Fig. 9A), as well as nascent reciprocal synapses engaging a labeled GC profile and a mitral cell dendritic profile (Fig. 9B), and GABAergic synapses, labeled with gephyrin, formed by immunonegative terminals onto eGFP-positive profiles (Fig. 9C). Furthermore, analysis of serial sections also revealed the existence of asymmetric synapses onto GC dendrite shaft profiles (Fig. 9D$G)$, confirming our light microscopy observations of "isolated" PSD-95 clusters onto dendritic shafts. Therefore, these results suggest that reciprocal synapses might be initiated, at least in part, on dendrites of GCs before outgrowth of a spine during final synaptic maturation. 


\section{Discussion}

The present results demonstrate that newborn GCs are rapidly targeted by inhibitory and excitatory axon terminals on leaving the migratory stream to populate the adult mouse OB. Functional synapses are established on both basal and apical dendrites in the GCL within $3 \mathrm{dpi}$, and on apical dendrites in the EPL $1 \mathrm{~d}$ later. Although the density of GABAergic inputs per dendrite unit length remains constant up to $7 \mathrm{dpi}$ in the GCL, the density of glutamatergic synapses doubles during the same period. Concomitant with the formation of synaptic inputs, we report a significant increase in spontaneous IPSC (sIPSC) amplitude and the establishment of output dendrodendritic synapses onto $\mathrm{M} / \mathrm{T}$ cells. Although these synapses are formed exclusively on spines of mature GCs, they were frequently seen on dendritic shafts in immature GCs. Furthermore, whereas dendrodendritic synapses are recognized morphologically by apposition of PSD-95 and GABA $_{\mathrm{A}} \mathrm{R} \alpha 1 / \alpha 3$ subunit clusters, isolated PSD-95 clusters were often seen in immature GC dendrites, suggesting a leading role for $\mathrm{M} / \mathrm{T}$ dendrites in initiating reciprocal synapse formation. Together, our findings indicate that synaptogenesis occurs very early at the proximal synapses when newborn neurons enter the OB circuit. Synaptogenesis precedes the morphological maturation of newborn GCs, with afferent input being functional before establishment of efferent connections.

\section{Methodological aspects}

To complete this morphological and electrophysiological analysis, we have used a PGK-eGFP lentivirus to transduce a sufficient number of newborn GCs. Since this approach also labels nondividing cells, we minimized the heterogeneity in cell age by performing the virus injection rostrally into the RMS, close to the entry into the $\mathrm{OB}$, where the population of migrating neuroblasts much exceeds the number of quiescent adult neural stem cells (Alonso et al., 2008). Such injections label a specific time-limited cohort of newborn OB interneurons, mainly comprised of GCs (Grubb et al., 2008; Nissant et al., 2009). Furthermore, we restricted our analysis to the first days after entry of newborn GCs into the $\mathrm{OB}$, much before any potentially transduced neural stem cells could give birth to neural precursors. At 3 dpi, eGFPpositive newborn cells already had basal and apical dendrites. Moreover, we observed a rapid morphological progression between 3 and $4 \mathrm{dpi}$, the earliest time point when newborn GCs extend their apical dendrite into the EPL. Morphologically and functionally, at $7 \mathrm{dpi}$, eGFP-positive cells corresponded to class 5 neurons described in previous studies (Petrenau and AlvarezBuylla, 2002; Carleton et al., 2003). Importantly, we performed the morphological analysis in slices prepared identically as for patch-clamp recordings to minimize any discrepancy resulting from dendritic or synaptic reorganization in acute slices during their preparation (Kirov et al., 2004). Therefore, our functional and morphological results are directly comparable with each

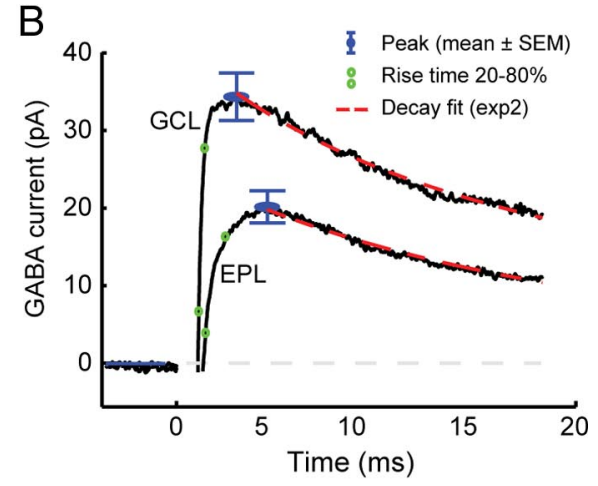

C EPL stimulation - Synapses in EPL and GCL - Synapses in GCL only

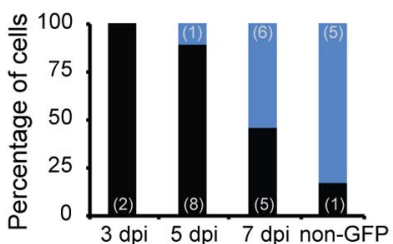

Figure 7. Formation of functional GABAergic synapses in the EPL. A1, Drawing illustrating the experimental setup to differentiate the responses from GCL and EPL synapses. A2, Voltage-clamp recordings from a newborn GC (7 dpi) of evoked GABAergic currents were evoked in distal synapses located in the EPL $B$ Mean traces recorded from a newborn neuron in the $G(L$ (7 dpi). top trace was obtained by $\mathrm{GCL}$ stimulation and could be blocked in the GCL (average of 21 traces). The bottom trace was obtained J 列 the GCL but not in the EPL (black). If the responses could also be blocked in the EPL, the cells were classified in the group having functional synapses in the GCL and EPL (blue).

other. Furthermore, this approach, based on a weak immersionfixation of living tissue slices, provides optimal detection of synaptic proteins and morphological preservation of eGFP-positive structures, including thin dendrites and spines (Schneider Gasser et al., 2006).

Previous studies (Whitman and Greer, 2007; Kelsch et al., 2008) used a different experimental approach, with retroviral injections in the SVZ and immunofluorescence staining of perfusion-fixed tissue. These studies reported a longer time delay between dendritic maturation and synapse formation than observed here. The reasons for this discrepancy are likely of technical nature, and might be related to the lower sensitivity of immunofluorescence in more strongly fixed tissue.

\section{Synaptic afferents precede synapse formation by} newborn GCs

Adult-generated GCs express voltage-gated channels when entering the GCL and receive functional GABAergic and glutamatergic synapses at this early stage. Although live imaging analysis might be required for determining whether synaptogenesis is initiated while the cells are still migrating, the elongated bipolar morphology of some GCs forming $\alpha 2 /$ gephyrin clusters strongly suggests that the first synapses are established before the cells reach their final position. Unexpectedly, density of inhibitory contacts is similar on the soma, basal dendrites and apical dendrite from 3 dpi onward, and does not change appreciably up to $7 \mathrm{dpi}$. Therefore, synaptic coverage along dendrites remains rather constant, despite the extensive and rapid growth of both basal and apical 

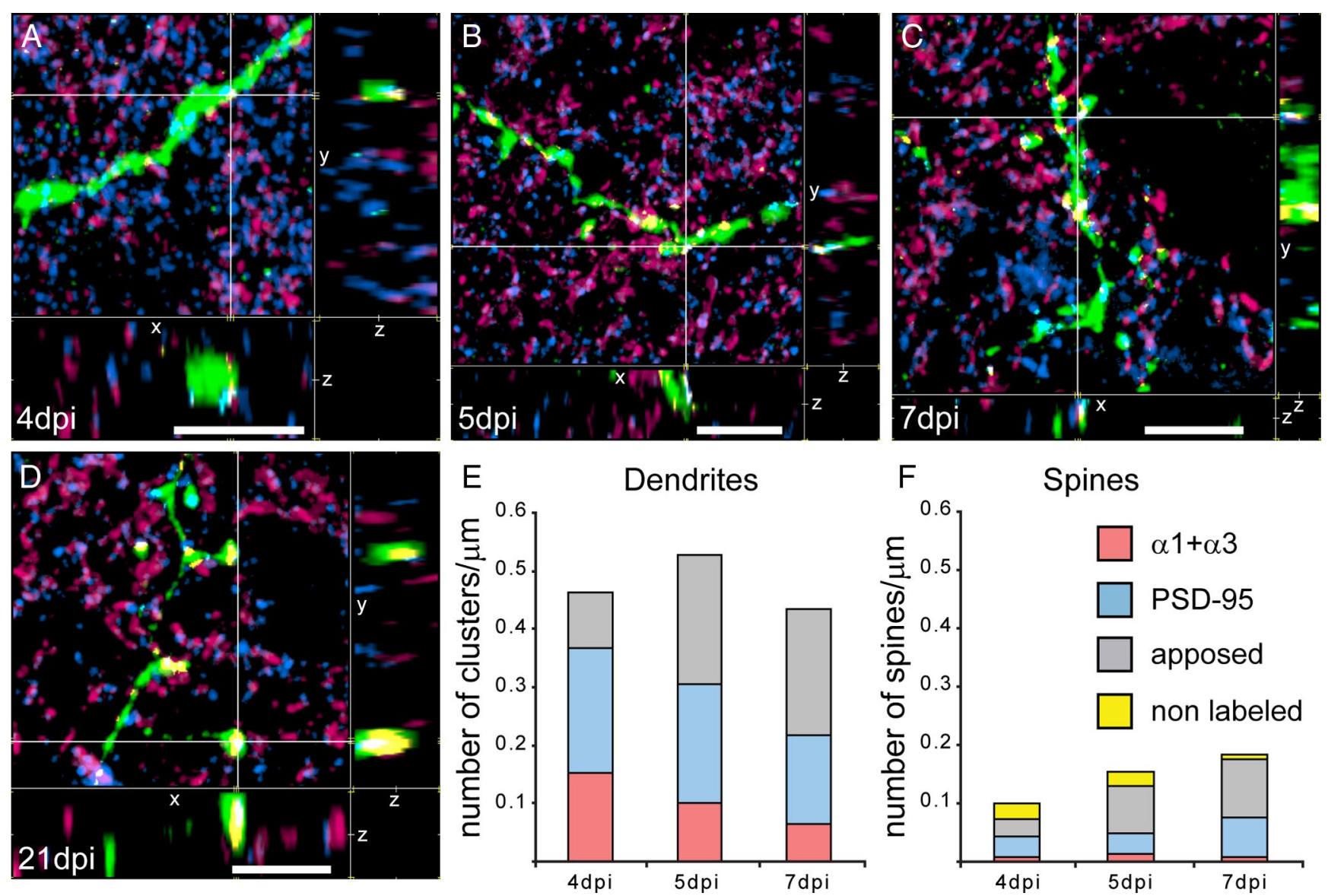

Figure 8. Formation of reciprocal synapses in the EPL. $\boldsymbol{A}-\boldsymbol{D}$, Double immunofluorescence staining for PSD-95 (blue) and $\alpha 1 / \alpha 3$ clusters (red) to visualize reciprocal synapses. The two markers are either closely apposed and overlap partially (appearing white) or separate (cyan or yellow) on eGFP-positive dendrites at $4-5$ dpi and on spine-like protrusions at 7 and 21 dpi. Each panel depicts at least one apposed cluster at the intersection of the $x y$ cross. The pictures are maximum intensity projections of confocal sections (7-16 layers spaced by $0.35 \mu \mathrm{m}$ ) depicted as three-dimensional images. Scale bars: $\boldsymbol{A}-\boldsymbol{F}, 5 \mu \mathrm{m}$. $\boldsymbol{E}$, Density of PSD-95, $\alpha 1 / \alpha 3$, and apposed clusters in eGFP-positive dendritic shaft at 4,5 , and $7 \mathrm{dpi}$. Although the total number of clusters remained constant between 4 and 7 dpi (one-way ANOVA, $p=0.2222$ ), the density of single labeled PSD-95 and $\alpha 1 / \alpha 3$ clusters decreased (Bonferroni's post test, $p<0.05$ ) because of rapid formation of apposed clusters (Bonferroni's post test, 7 vs 4 dpi, $p<0.001 ; 5$ vs 4 dpi, $p<0.001$ ). In addition, at 4 dpi we observed more PSD-95 clusters "alone" than apposed clusters (Bonferroni's post test, $p<0.05$ ). $\boldsymbol{F}$, Quantification of spine density and labeling in the same dendrites as in $\boldsymbol{E}$ ). The number of spines increased significantly with time (one-way ANOVA, $F_{(2,92)}=3.622 ; p=0.0307$ ). Although not all spines were labeled, a significant increase in the density of apposed clusters was seen at 5 and $7 \mathrm{dpi}$ compared with $4 \mathrm{dpi}$ (Bonferroni's post test, $p<0.001$ ). The density of apposed clusters became significantly higher than single labeled clusters at $5 \mathrm{dpi}$ (Bonferroni's post test, $p<0.05$ ). At $7 \mathrm{dpi}$, spines with apposed clusters were significantly more numerous than spines labeled with $\alpha 1 / \alpha 3$ clusters and nonlabeled spines (Bonferroni's post test, $p<0.05$ ).

Table 2. Density of reciprocal synapses in the EPL, visualized by clusters of PSD-95, $\alpha 1 / \alpha 3$ subunit, and PSD-95 apposed to $\alpha 1 / \alpha 3$ subunit

\begin{tabular}{|c|c|c|c|c|c|}
\hline & PSD-95 & $\alpha 1 \alpha 3$ & Apposed & Nonlabeled & Total \\
\hline \multicolumn{6}{|c|}{ Quantification on dendritic shafts } \\
\hline $4 \mathrm{dpi}$ & $0.21 \pm 0.02^{\dagger \dagger}$ & $0.15 \pm 0.02$ & $0.10 \pm 0.01$ & & \\
\hline $5 \mathrm{dpi}$ & $0.20 \pm 0.02^{\S}$ & $0.10 \pm 0.01^{\ddagger}$ & $0.22 \pm 0.03^{* *}$ & & \\
\hline $7 \mathrm{dpi}$ & $0.15 \pm 0.01^{\S \S \dagger}$ & $0.07 \pm 0.01^{\circ \neq}$ & $0.21 \pm 0.02^{\circ \circ}$ & & \\
\hline \multicolumn{6}{|c|}{ Quantification on spines } \\
\hline $4 \mathrm{dpi}$ & $0.04 \pm 0.01^{\S}$ & $0.007 \pm 0.003$ & $0.03 \pm 0.007$ & $0.03 \pm 0.006$ & $0.1 \pm 0.02$ \\
\hline $5 \mathrm{dpi}$ & $0.04 \pm 0.01^{\dagger}$ & $0.01 \pm 0.004^{\ddagger}$ & $0.10 \pm 0.01^{* *}$ & $0.03 \pm 0.007^{\alpha}$ & $0.15 \pm 0.02$ \\
\hline $7 \mathrm{dpi}$ & $0.07 \pm 0.01^{\S \S \S}$ & $0.007 \pm 0.003^{\ddagger}$ & $0.10 \pm 0.02^{\circ \circ}$ & $0.01 \pm 0.003^{¥ 0 \alpha x}$ & $0.19 \pm 0.02$ \\
\hline
\end{tabular}

Clusters were distinguished based on whether PSD-95 or $\alpha 1 / \alpha 3$ subunit were either alone or apposed to each other. At the top ("Quantification on dendritic shafts"), the density of clusters formed on the shaft (mean \pm SD) is given per micrometer/dendrite length. At the bottom ("Quantification on spines"), the density of spines (mean \pm SD) per micrometer/dendrite length is given based on the type of cluster apposed to the spine. The density of unlabeled spines and the total spine density are indicated in the last two columns. The symbols indicate the results of Bonferroni's post hoc tests (for main statistical analysis, see Results).

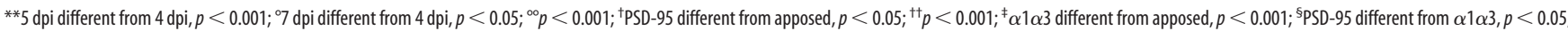
${ }^{\S \S} p<0.01 ;{ }^{\S \S} p<0.001 ;$; ${ }^{*}$ nonlabeled different from PSD-95, $p<0.001$; "nonlabeled different from apposed, $p<0.01 ;{ }^{\text {wa }} p<0.001$.

dendrites, indicating that the total number of synapses received by newborn GCs increases between 3 and 7 dpi. The increased amplitude of evoked synaptic currents and the increased frequency of spontaneous events, without change in their amplitude between 3 and $7 \mathrm{dpi}$, suggest that the total number of GABAergic contacts grows with maturation. However, because we did not analyze miniature events (i.e., synaptic events recorded in the presence of TTX), we cannot rule out change in excitability of the presynaptic neurons. Nevertheless, this later possibility is unlikely since the host circuit is supposed to be already mature at the time when newborn neurons arrive (i.e., slices were prepared from at least 2-month-old animals). 
The increased amplitude of unitary currents between 3 and 7 dpi indicates that the strength of inhibition increases over the time. Although GABAergic innervation of GCs has received little attention so far, our results suggest that the density of GABAergic synapses on GC dendrites is only slightly less than glutamatergic synapses at $7 \mathrm{dpi}$, when maturation is already well advanced. Interestingly, glutamatergic synapses appear in two stages, with an initial set being established at $3 \mathrm{dpi}$ and the rest being formed up to $7 \mathrm{dpi}$. The second stage coincides temporally with the development of reciprocal synapses in the EPL. It is tempting to speculate that the two stages correspond to distinct types of afferents (e.g., centrifugal afferents and M/T collaterals). In any case, the basic synaptic circuit characteristic of mature GCs is established within a few days after migrating into the GCL. These results, although differing in the timing and nature of synaptogenesis, confirm previous suggestions that adult-generated GCs receive synaptic input before their integration into the circuitry in the EPL (Whitman and Greer, 2007; Kelsch et al., 2008). However, a major difference with this previous study is that GABAergic innervation predominates, at least numerically, at the earliest steps of synaptogenesis, a yetunseen process.

The establishment of functional synapses at early stages of GC maturation might offer a substrate for experience-dependent regulation of adult neurogenesis that could be crucial for their long-term survival, as shown on blockade of glutamatergic activity during development (de Lima et al., 2004; Gascon et al., 2006).

\section{Functional properties of GABAergic synapses onto newborn GCs}

Mechanisms regulating adult neurogenesis are often considered to be similar to those operating during ontogenetic development (Wang and Kriegstein, 2009) when $\mathrm{GABA}_{\mathrm{A}}$ Rs are known to regulate early stages of neurogenesis (Wang and Kriegstein, 2008). During ontogenesis, the subunit composition of $\mathrm{GABA}_{\mathrm{A}} \mathrm{R}$ changes, possibly reflecting functional adaptations during maturation of neuronal circuits. In contrast, our data indicate GCs already expressed postsynaptic $\alpha 2-\mathrm{GABA}_{\mathrm{A}} \mathrm{R}$ clustered with gephyrin after $3 \mathrm{dpi}$, like mature GCs. Furthermore, the properties (rise and decay time kinetics) of sIPSCs did not change during GC maturation, indicating that GABAergic synapses formed onto newborn GCs do not go through a phase of functional maturation accompanied by a change in subunit composition. It remains to be determined, however, whether the effects of GABA change in developing GCs in dependence of $\mathrm{Cl}^{-}$gradients established by NKCC1 and KCC2 (Blaesse et al., 2009). In particular, there is evidence that overexpression of KCC2 coincides with the end of migration of interneurons in developing neocortex (Bortone and Polleux, 2009). We have attempted to determine the onset of KCC2 expression in newborn GCs by immunofluorescence; however, the high neuronal density in the GCL precluded the determination of its precise cellular localization (P. Panzanelli and J.-M. Fritschy, unpublished observations).

\section{Mechanisms of synapse formation}

In cortical neurons, live imaging studies and EM reconstruction analysis indicated that excitatory synapses form on spine-like structures, whereas GABAergic synapses are established on dendritic shafts (Knott et al., 2006; Nikonenko et al., 2008; Wierenga et al., 2008). Our present results provide a different picture, by showing the presence of presynaptic and postsynaptic proteins of GABAergic synapses on spine-like protrusions in both the IPL and EPL. In mature GCs, spines are recipients of glutamatergic synapses in the GCL and reciprocal synapses in the EPL. Therefore, these early GABAergic synapses, confirmed ultrastructurally (Fig. 9C), might be transient and precede formation of stable GABAergic synapses on dendritic shafts. Conversely, formation of reciprocal synapses might occur, at least in part, on the shaft of immature distal GC dendrites. First, we observed a higher number of PSD-95 clusters apposed to $\alpha 1 / \alpha 3$ subunit clusters in eGFP-positive dendrites than in spines. Second, very few spinelike protrusions devoid of PSD-95 or $\alpha 1 / \alpha 3$ staining were seen (representing "synapse-less" spines). Third, ultrastructural analysis also revealed the presence of asymmetric synapses formed by mitral cell dendrites onto eGFP-positive GC dendrites. Therefore, reciprocal synapses might be assembled on dendrites before spine formation at these sites. Alternatively, reciprocal synapses on the shaft might be transient and rapidly replaced by reciprocal synapses on spines, which clearly predominate at later stages (21 dpi) (Fig. 8D). 
At 4 dpi, the PSD-95 clusters "alone" were significantly more abundant than the PSD-95 clusters apposed to $\alpha 1 / \alpha 3$ subunit clusters, whereas, at 5 and $7 \mathrm{dpi}$ we did not observe a significant difference between these two populations of clusters. These data suggest that the glutamatergic component might be assembled shortly before the GABAergic component, confirming an early hypothesis that the asymmetric synapse forms before the symmetric synapse in dendrodendritic contacts (Hinds and Hinds, 1976a,b).

\section{Conclusions}

Synaptogenesis appears tightly linked with morphological and functional maturation of newborn GCs in adult mouse OB. Extending previous work on the role of "ambient" GABA (Ge et al., 2007; Platel et al., 2008), likely operating through extrasynaptic $\mathrm{GABA}_{\mathrm{A}} \mathrm{R}$ expressed by neural progenitor cells, our findings indicate that synapses are formed first into the GCL and then into EPL, with initial predominance of GABAergic versus glutamatergic synaptic transmission. Afferent synapses onto newborn GC are formed before their apical dendrite reaches the EPL, providing unequivocal evidence for the presence of GABAergic and glutamatergic influences before formation of output synapses onto M/T cells. Nevertheless, efferent synapses, in the form of the GABAergic moiety of reciprocal synapses onto M/T dendrites, are likewise established very soon after ingrowth of GC dendrites into the EPL, possibly under the influence of the glutamatergic moiety. Therefore, the overall synaptic weight contacting the developing apical dendrite shifts from predominant GABAergic inputs onto the proximal portion (i.e., GCL inputs) to predominant glutamatergic inputs onto the distal portion (i.e., EPL inputs). This sequence of synapse formation is similar to that reported during brain development (Hennou et al., 2002), suggesting that GABAergic control of neuronal activity needs being established before formation of AMPA excitatory synapses. Therefore, the precise spatiotemporal orchestration of the synaptic integration of newborn GCs might be a key to successful differentiation and long-term maturation in adult neuronal circuits.

\section{References}

Alonso M, Ortega-Pérez I, Grubb MS, Bourgeois JP, Charneau P, Lledo PM (2008) Turning astrocytes from the rostral migratory stream into neurons: a role for the olfactory sensory organ. J Neurosci 28:11089-11102.

Altman J (1969) Autoradiographic and histological studies of postnatal neurogenesis. IV. Cell proliferation and migration in the anterior forebrain, with special reference to persisting neurogenesis in the olfactory bulb. J Comp Neurol 137:433-457.

Alvarez-Buylla A, Garcia-Verdugo JM (2002) Neurogenesis in adult subventricular zone. J Neurosci 22:629-634.

Balu R, Pressler RT, Strowbridge BW (2007) Multiple modes of synaptic excitation of olfactory bulb granule cells. J Neurosci 27:5621-5632.

Belluzzi O, Benedusi M, Ackman J, LoTurco JJ (2003) Electrophysiological differentation of new neurons in the olfactory bulb. J Neurosci 23:10411-10418.

Blaesse P, Airaksinen MS, Rivera C, Kaila K (2009) Cation-chloride cotransporters and neuronal function. Neuron 61:820-838.

Bordey A (2007) Enigmatic GABAergic networks in adult neurogenic zones. Brain Res Rev 53:124-134.

Bortone D, Polleux F (2009) KCC2 expression promotes the termination of cortical interneuron migration in a voltage-sensitive calcium-dependent manner. Neuron 62:53-71.

Carleton A, Petreanu LT, Lansford R, Alvarez-Buylla A, Lledo PM (2003) Becoming a new neuron in the adult olfactory bulb. Nat Neurosci 6:507-518.

Consiglio A, Gritti A, Dolcetta D, Follenzi A, Bordignon C, Gage FH, Vescovi AL, Naldini L (2004) Robust in vivo gene transfer into adult mammalian neural stem cells by lentiviral vectors. Proc Natl Acad Sci U S A 101:14835-14840. de Lima AD, Opitz T, Voigt T (2004) Irreversible loss of a subpopulation of cortical interneurons in the absence of glutamatergic network activity. Eur J Neurosci 19:2931-2943.

Eyre MD, Antal M, Nusser Z (2008) Distinct deep short-axon cell subtypes of the main olfactory bulb provide novel intrabulbar and extrabulbar GABAergic connections. J Neurosci 28:8217-8229.

Eyre MD, Kerti K, Nusser Z (2009) Molecular diversity of deep short-axon cells of the rat main olfactory bulb. Eur J Neurosci 29:1397-1407.

Fritschy JM, Mohler H (1995) $\mathrm{GABA}_{\mathrm{A}}$-receptor heterogeneity in the adult rat brain: differential regional and cellular distribution of seven major subunits. J Comp Neurol 359:154-194.

Fritschy JM, Paysan J, Enna A, Mohler H (1994) Switch in the expression of rat $\mathrm{GABA}_{\mathrm{A}}$-receptor subtypes during postnatal development: an immunohistochemical study. J Neurosci 14:5302-5324.

Gascon E, Dayer AG, Sauvain MO, Potter G, Jenny B, De Roo M, Zgraggen E, Demaurex N, Muller D, Kiss JZ (2006) GABA regulates dendritic growth by stabilizing lamellipodia in newly generated interneurons of the olfactory bulb. J Neurosci 26:12956-12966.

Ge S, Pradhan DA, Ming GL, Song H (2007) GABA sets the tempo for activity-dependent adult neurogenesis. Trends Neurosci 30:1-8.

Grubb MS, Nissant A, Murray K, Lledo PM (2008) Functional maturation of the first synapse in olfaction: development and adult neurogenesis. J Neurosci 28:2919-2932.

Hennou S, Khalilov I, Diabira D, Ben-Ari Y, Gozlan H (2002) Early sequential formation of functional GABAA and glutamatergic synapses on CA1 interneurons of the rat foetal hippocampus. Eur J Neurosci 16:197-208.

Hinds JW, Hinds PL (1976a) Synapse formation in the mouse olfactory bulb. I. Quantitative studies. J Comp Neurol 169:15-40.

Hinds JW, Hinds PL (1976b) Synapse formation in the mouse olfactory bulb. II. Morphogenesis. J Comp Neurol 169:41-61.

Kashiwadani H, Sasaki YF, Uchida N, Mori K (1999) Synchronized oscillatory discharges of mitral/tufted cells with different molecular receptive ranges in the rabbit olfactory bulb. J Neurophysiol 82:1786-1792.

Kelsch W, Lin CW, Lois C (2008) Sequential development of synapses in dendritic domains during adult neurogenesis. Proc Natl Acad Sci U S A 105:16803-16808.

Kempermann G, Jessberger S, Steiner B, Kronenberg G (2004) Milestones of neuronal development in the adult hippocampus. Trends Neurosci 27:447-452.

Kirov SA, Petrak LJ, Fiala JC, Harris KM (2004) Dendritic spines disappear with chilling but proliferate excessively upon rewarming of mature hippocampus. Neuroscience 127:69-80.

Knott GW, Holtmaat A, Wilbrecht L, Welker E, Svoboda K (2006) Spine growth precedes synapse formation in the adult neocortex in vivo. Nat Neurosci 9:1117-1124.

Kollo M, Holderith N, Antal M, Nusser Z (2008) Unique clustering of A-type potassium channels on different cell types of the main olfactory bulb. Eur J Neurosci 27:1686-1699.

Lagier S, Carleton A, Lledo PM (2004) Interplay between local GABAergic interneurons and relay neurons generates gamma oscillations in the rat olfactory bulb. J Neurosci 24:4382-4392.

Lagier S, Panzanelli P, Russo RE, Nissant A, Bathellier B, Sassoè-Pognetto M, Fritschy JM, Lledo PM (2007) GABAergic inhibition at dendrodendritic synapses tunes gamma oscillations in the olfactory bulb. Proc Natl Acad Sci U S A 104:7259-7264.

Laurie DJ, Seeburg PH, Wisden W (1992) The distribution of $13 \mathrm{GABA}_{\mathrm{A}}$ receptor subunit mRNAs in the rat brain. II. Olfactory bulb and cerebellum. J Neurosci 12:1063-1076.

Lledo PM, Lagier S (2006) Adjusting neurophysiological computations in the adult olfactory bulb. Semin Cell Dev Biol 17:443-453.

Lledo PM, Alonso M, Grubb MS (2006) Adult neurogenesis and functional plasticity in neuronal circuits. Nat Rev Neurosci 7:179-193.

Ming GL, Song H (2005) Adult neurogenesis in the mammalian central nervous system. Annu Rev Neurosci 28:223-250.

Nikonenko I, Boda B, Steen S, Knott G, Welker E, Muller D (2008) PSD-95 promotes synaptogenesis and multiinnervated spine formation through nitric oxide signaling. J Cell Biol 183:1115-1127.

Nissant A, Bardy C, Katagiri H, Murray K, Lledo PM (2009) Adult neurogenesis promotes synaptic plasticity in the olfactory bulb. Nat Neurosci 12:728-730.

Nusser Z, Kay LM, Laurent G, Homanics GE, Mody I (2001) Disruption of 
$\mathrm{GABA}_{\mathrm{A}}$ receptors on GABAergic interneurons leads to increased oscillatory power in the olfactory bulb network. J Neurophysiol 86:2823-2833.

Panzanelli P, Perazzini AZ, Fritschy JM, Sassoè-Pognetto M (2005) Heterogeneity of $\gamma$-aminobutyric acid type A receptors in mitral and tufted cells of the rat main olfactory bulb. J Comp Neurol 484:121-131.

Panzanelli P, Fritschy JM, Yanagawa Y, Obata K, Sassoè-Pognetto M (2007) GABAergic phenotype of periglomerular cells in the rodent olfactory bulb. J Comp Neurol 502:990-1002.

Petrenau L, Alvarez-Buylla A (2002) Maturation and death of adult-born olfactory bulb granule neurons: role of olfaction. J Neurosci 22:6106-6113.

Pirker S, Schwarzer C, Wieselthaler A, Sieghart W, Sperk G (2000) GABA A receptors: immunocytochemical distribution of 13 subunits in the adult rat brain. Neuroscience 101:815-850.

Platel JC, Dave KA, Bordey A (2008) Control of neuroblast production and migration by converging GABA and glutamate signals in the postnatal forebrain. J Physiol 586:3739-3743.

Sassoè-Pognetto M, Panzanelli P, Sieghart W, Fritschy JM (2000) Colocalization of multiple $\mathrm{GABA}_{\mathrm{A}}$ receptor subtypes with gephyrin at postsynaptic sites. J Comp Neurol 420:481-498.

Schneider Gasser EM, Straub CJ, Panzanelli P, Weinmann O, SassoèPognetto M, Fritschy JM (2006) Immunofluorescence in brain sections: simultaneous detection of presynaptic and postsynaptic proteins in identified neurons. Nat Protoc 1:1887-1897.

Shepherd GM, Chen WR, Greer CA (2004) Olfactory bulb. In: The synaptic organization of the brain, Ed 5 (Shepherd GM, ed), pp 165-216. New York: Oxford UP.

Tamamaki N, Yanagawa Y, Tomioka R, Miyazaki J, Obata K, Kaneko T (2003) Green fluorescent protein expression and colocalization with calretinin, parvalbumin, and somatostatin in the GAD67-GFP knock-in mouse. J Comp Neurol 467:60-79.

Wang DD, Kriegstein AR (2008) GABA regulates excitatory synapse formation in the neocortex via NMDA receptor activation. J Neurosci 28:5547-5558.

Wang DD, Kriegstein AR (2009) Defining the role of GABA in cortical development. J Physiol 587:1873-1879.

Whitman MC, Greer CA (2007) Synaptic integration of adult-generated olfactory bulb granule cells: basal axodendritic centrifugal input precedes apical dendrodendritic local circuits. J Neurosci 27:9951-9961.

Wierenga CJ, Becker N, Bonhoeffer T (2008) GABAergic synapses are formed without the involvement of dendritic protrusions. Nat Neurosci 11:1044-1052. 